\title{
Fatores Associados à Evasão no Ensino Superior Brasileiro: um estudo de análise de sobrevivência para os cursos das áreas de Ciência, Matemática e Computação e de Engenharia, Produção e Construção em instituições públicas e privadas
}

\author{
Alice Saccaro ${ }^{1}$ \\ Marco Túlio Aniceto França ${ }^{2}$ \\ Paulo de Andrade Jacinto ${ }^{3}$
}

\begin{abstract}
Resumo
A escassez de profissionais do campo das ciências naturais e engenharias atinge diversos países. No Brasil, uma das causas para esse fenômeno é a alta evasão de estudantes de cursos de ensino superior dessa área. Em função dos cursos das instituições públicas e de parte significativa dos empréstimos e bolsas de estudo ofertadas no ensino privado serem custeados por recursos governamentais, torna-se importante avaliar os motivos que causam o elevado abandono. Portanto, o objetivo deste artigo consiste em analisar variáveis que influenciam na evasão. O método utilizado é o de Análise de Sobrevivência, por meio das bases de dados do Censo da Educação Superior dos anos de 2009 a 2014. Como resultado, percebe-se que a evasão é maior nas instituições privadas. Ser homem e ter mais idade diminui o tempo de vida do indivíduo no ensino superior, enquanto que alunos contemplados com apoio financeiro apresentam uma maior retenção.
\end{abstract}

\section{Palavras-Chave}

Evasão. Ensino superior. Ciências Naturais. Engenharia. Análise de sobrevivência.

\footnotetext{
Abstract

The shortage of professionals in the field of natural sciences and engineering is a problem that reaches many countries. In Brazil, one of the reasons for this is the significant dropout rates that the courses of the field in the tertiary education present. Since the courses of public

1 Doutoranda em Economia - Universidade Federal Fluminense (UFF).

Endereço: Rua Alexandre Moura, 8 - Bloco F - São Domingos - Niterói/RJ - Brasil.

CEP: 24210-200 - E-mail: ali.saccaro@gmail.com - ORCiD: https://orcid.org/0000-0001-9179-099X.

2 Professor - Pontifícia Universidade Católica do Rio Grande do Sul (PUCRS).

Endereço: Av. Ipiranga, 6681 - Prédio 50 - Partenon - Porto Alegre/RS - Brasil - CEP: 90619-900.

E-mail: marco.franca@pucrs.br - ORCiD: https://orcid.org/0000-0003-1865-323X.

3 Professor - Universidade Federal do Paraná (UFPR).

Endereço: Av. Prefeito Lothário Meissner, 632 - Térreo - Jardim Botânico - Curitiba/PR - Brasil. CEP: 80210-170 - E-mail: paulo.jacinto@ufpr.br -ORCiD: http://orcid.org/0000-0002-8563-9190. Recebido: 07/01/2017. Aceite: 06/02/2019.
}

(c) (i) (\$) Esta obra está licenciada com uma Licença Creative Commons Atribuição-Não Comercial 4.0 Internacional. 
institutions and the financial support offered to students from private institutions are paid with governmental resources, it is important to evaluate the reasons that lead to abandon. Thus, this article seeks to analyze the dropout rates of these courses, studying covariates that influence on this decision. The method employed is the Survival Analysis, and the dataset used is the Tertiary Education Survey from 2009 to 2014. As results, it is found that the dropout rates are higher in private colleges. Men and older students present a negative time ratio, but the indexes are positive if the student receives financial support.

\section{Keywords}

Dropout. Tertiary education. Natural Science. Engineering. Survival analysis.

\section{JEL Classification}

C41. H52. 128.

\section{Introdução}

A partir do início da década de 2000, o governo federal brasileiro passou a investir na ampliação do acesso ao ensino superior por meio de diversas medidas, tanto na esfera privada quanto na pública. No âmbito das instituições privadas, foram criados o Fundo de Financiamento ao Estudante do Ensino Superior (FIES) e o Programa Universidade para Todos (PROUNI). Para as instituições públicas de ensino foi criado o Programa de Apoio aos Planos de Reestruturação e Expansão das Universidades Federais (REUNI) em 2007, cuja meta era ampliar o acesso e a permanência dos estudantes nessas instituições. Para combater a evasão, foi instituído o Programa Nacional de Assistência Estudantil (PNAES), responsável por diversos benefícios como o auxílio moradia, auxílio alimentação, entre outros (BRASIL 2012).

A quantidade de alunos matriculados no ensino superior em cursos presenciais passou de 4.676.646, em 2006, para 5.115.896, em 2009, e 6.776.049, em 2014, perfazendo um aumento de 44,89\% entre 20062014. ${ }^{1}$ Todavia, no Brasil o número de graduados anualmente ainda é con-

1 Paralelo a essa expansão, houve um crescimento expressivo na quantidade de recursos públicos investidos nesse setor. Em 2006, ano anterior à criação do REUNI, o orçamento das universidades federais era de $\mathrm{R} \$ 14,5$ bilhões, sendo que esse valor passou para 25,9 bilhões em 2012 (BRASIL 2010, BRASIL 2012). Para o caso do PROUNI, a estimativa da renúncia de receita das entidades privadas que aderiram ao programa passou de $\mathrm{R} \$ 106,7$ milhões, em 2005, para R $\$ 751$ milhões, em 2013 (BRASIL 2015b). Para o FIES foram descentralizados R \$ 861,93 milhões no ano de 2000, 
siderado baixo quando comparado com outros países. Segundo dados da OCDE (2015), em 2012, 29\% dos graduados da Coreia do Sul, 28\% da Alemanha, 37\% da França eram oriundos das ciências naturais e engenharia, ao passo que no Brasil esse percentual era apenas de $11 \%$.

A baixa qualidade do ensino básico, o nível de dificuldade do curso e os poucos recursos investidos nas universidades para a formação desses profissionais são algumas das razões apontadas pela literatura internacional para esse fenômeno. Para o Brasil, um dos motivos apontados consiste nas altas taxas de evasão dos cursos das áreas de Ciência, Matemática e Computação e Engenharia, Produção e Construção. Segundo dados do Censo da Educação Superior entre 2009 e 2014, a graduação em Direito acumulou uma evasão de aproximadamente $45 \%$ ao longo desses anos, enquanto os cursos de Matemática e os de Engenharias Metalúrgica e Mecânica apresentaram, nesse mesmo período, taxas próximas aos $90 \%$ e 60\%, respectivamente. (INEP 2009, INEP 2010 a, INEP 2011, INEP 2012b, INEP 2013a e INEP 2014a).

Essa informação gera preocupação, na medida em que os cursos das áreas de setores como engenharia e ciências naturais estão diretamente relacionados com parte significativa da geração de inovações tecnológicas e com o aumento de produtividade. A considerar apenas a questão numérica, a baixa quantidade de pessoal qualificado pode impactar negativamente na economia brasileira. Ou seja, a sociedade, de uma forma geral, não poderá contar com as externalidades positivas que poderiam ser geradas por esses profissionais. Assim, dado a importância de profissionais formados nessas áreas, uma análise da evasão dos alunos das categorias Ciência, Matemática e Computação e Engenharia, Produção e Construção, permitiria gerar informações a respeito do perfil e ao mesmo tempo entender um pouco mais as razões para tal evasão.

A evasão no ensino superior tem sido um tema frequente nas discussões e elaboração de políticas públicas no Brasil há quase 20 anos. $^{2}$ Porém, ainda

enquanto que em 2013, os gastos com o programa foram de R \$12,2 bilhões. Nesse último ano, 35\% dos estudantes do ensino privado contavam com o apoio desse sistema de financiamento para custear pelo menos uma parte dos custos dos seus estudos (BRASIL 2001, BRASIL 2015c).

2 A discussão a respeito da evasão no ensino superior brasileiro teve início na década de 1990. A sua entrada na agenda governamental ocorreu a partir da publicação do Seminário sobre evasão nas universidades brasileiras, da Secretaria de Educação Superior do Ministério da Educação (SESU/ MEC) em 1995. No ano de 1996 ocorreu o lançamento do estudo Diplomação, Retenção e Evasão nos Cursos de Graduação em Instituições de Ensino Superior Públicas. Fruto de um trabalho coletivo que envolvia $77,2 \%$ do universo da educação superior pública do país, esse documento apresentava 
não foram obtidos resultados satisfatórios. Normalmente, a evasão é vista por uma perspectiva negativa, em que é considerado o volume de gastos do governo, associando-a com a perda de recursos públicos quando os estudantes evadem. ${ }^{3}$ Isso é natural, tendo em vista que no caso do Brasil, os cursos das instituições públicas e uma parte significativa das bolsas de estudo e financiamentos ofertados para estudantes do ensino privado são custeados com recursos públicos. Contudo, a evasão pode ser entendida como sendo um fenômeno não necessariamente ruim, já que pode ocorrer uma melhora na escolha dos cursos por parte dos estudantes. No cenário atual de contenção de despesas, em que há escassez de recursos que possam ser destinados a essa esfera de ensino, a primeira perspectiva acaba sendo predominante. Mas, independente de qual delas se sobressai, torna-se importante entender as razões que influenciam na evasão do ensino superior.

Para ANDIFES/ABRUEM/SESU/MEC (1996), a evasão pode ocorrer relativamente a curso, instituição e do próprio sistema de ensino superior. Neste estudo serão analisados os dois primeiros níveis, isto é, será considerada como evasão a situação em que os alunos se transferiram de curso ou se desvincularam da instituição. Indivíduos com a matrícula trancada não serão considerados evadidos, porque mesmo que eles tenham se afastado por um determinado período da instituição, alguns retornaram, enquanto outros abandonam os cursos definitivamente. Além disso, quando o aluno se desvincula da instituição ou tranca a matrícula, mas entra em outro curso, seu código identificador no Censo da Educação Superior muda. Isso torna difícil o estudo do abandono definitivo do ensino superior.

Dessa forma, o objetivo deste estudo é analisar quais os fatores associados à evasão de estudantes que ingressaram no ano de 2009 nos cursos das áreas de Ciências, Matemática e Computação e Engenharia, Produção e Construção do ensino superior brasileiro. A análise faz uso de uma amostra dividida em matriculados em cursos de quatro e de cinco anos de duração, presenciais, de instituições públicas e privadas obtidas do Censo da Educação Superior dos anos de 2009 a 2014. O método utilizado consiste na Análise de Sobrevivência, na medida em que essa metodologia permite estudar o tempo entre a entrada do estudante na universidade e o momento em que ele sai por alguma forma de abandono.

dados significativos a respeito do desempenho das universidades públicas em relação aos índices de retenção, diplomação e evasão dos alunos dos cursos de graduação (BRASIL 1995, BRASIL 1996).

3 Para o ano de 2008, o custo anual de um estudante de ensino superior em uma instituição federal foi de aproximadamente $\mathrm{R} \$ 14.763,00$ (INEP 2010b). 
Além desta breve introdução, o presente trabalho está dividido em cinco seções. Na segunda seção é realizada uma síntese da literatura sobre a evasão no ensino superior, além de breve discussão sobre o abandono dos cursos da área de ciências naturais, engenharia e tecnologia, dando ênfase para os motivos que levam os alunos a abandonarem os estudos. Na terceira seção descreve-se a metodologia de Análise de Sobrevivência. Na quarta, são apresentadas as fontes dos dados e as estatísticas descritivas. Por fim, na última seção, são apresentados os resultados e são realizadas as considerações finais.

\section{Evasão no Ensino Superior: uma síntese da literatura}

Os estudos a respeito da evasão no ensino superior brasileiro são escassos quando comparados à literatura sobre o tema nos Estados Unidos e Europa. Para os Estados Unidos, Bound, Lovenheim e Turner (2009) demonstram que, apesar da quantidade de alunos que ingressaram no ensino superior ter aumentado nos anos 1990, em comparação com a década de 1970, as taxas de evasão também cresceram. A diminuição dos recursos empregados por aluno e o fato de que a expansão de vagas ter permitido que indivíduos não tão bem preparados no ensino médio também ingressassem no ensino superior são apontados pelos autores como fatores que influenciaram o abandono de cursos.

Para o caso de evasão, Stinebrickner e Stinebrickner (2013b), com o uso de um Dynamic Learning Model, avaliam que notas obtidas pelos estudantes de universidades comunitárias no decorrer do curso influenciam a decisão de abandoná-lo. A evasão também é afetada pelo fato de que o baixo desempenho diminui o retorno financeiro de continuar estudando. Utilizando o método de Análise de Sobrevivência, Murtaugh, Burns e Schuster (1999) avaliam a retenção de alunos de uma universidade no estado do Oregon e encontram que estudantes com menores notas também possuem maiores chances de evadir.

Para Stinebricker e Stinebricker (2013a) além da importância da educação de base, também é relevante que alunos ingressantes tenham a percepção correta sobre o nível de preparação necessário para ter um bom desempenho no seu curso. Isso poderia aumentar o esforço do aluno nos primeiros 
anos, o que ajudaria a diminuir a evasão. Smith e Naylor (2001) também mostram que a educação recebida antes de ingressar na faculdade tem impacto nas taxas de abandono. Bound, Lovenheim e Turner (2009) avaliam que a diminuição no preparo de alunos antes de entrar na universidade influencia nas taxas de evasão crescentes nos cursos. Além disso, tanto Stinebricker e Stinebricker (2013a) e Bound, Lovenheim e Turner (2009) mostram que as mulheres abandonam menos os cursos do que os homens. Nesse sentido, Smith e Naylor (2001) apresentam que essas taxas não são homogêneas: elas variam conforme o curso e o gênero.

Outra literatura encontrada refere-se ao abandono de cursos de ciências naturais e engenharia. Para o caso norte-americano, país em que se encontrou a maior quantidade de trabalhos, Chen e Soldner (2013) apontam na sua pesquisa que $56 \%$ dos alunos que estavam no primeiro ano de ensino superior e matriculados nas áreas de ciência e tecnologia trocaram de curso em um período de seis anos. Além disso, expectativas a respeito do curso, formação na educação básica e notas obtidas nos primeiros semestres influenciam a decisão de evadir. Felder et al. (1993), por meio do emprego de testes de qui-quadrado para avaliar a relação entre as variáveis, analisam quais características influenciaram na repetência de disciplinas do primeiro semestre de um curso de engenharia química, algo que poderia induzir a evasão futura. A sua conclusão é que alunos que participam de atividades extracurriculares por até 12 horas semanais, e que são de regiões urbanas, têm chances menores e estatisticamente significantes de abandonar o curso.

Os alunos que trabalham mais de 10 horas semanais, aqueles que acreditam que a sua preparação acadêmica para o curso foi abaixo da média ou que os pais não possuem diploma de ensino superior tem probabilidade maior e estatisticamente significante de repetir as disciplinas, e consequentemente, abandonar o curso. Chen e Soldner (2013) também encontra que, a preparação que o aluno teve antes de entrar na faculdade é correlacionada com a decisão de largar o curso. Além disso, ele verifica que alunos homens, que vieram de uma família em condição de vulnerabilidade social e que ingressaram em universidades menos conceituadas têm maiores chances de evadir do que mulheres, de classe abastada e matriculadas em instituições renomadas. 
Já para analisar a evasão do sistema de ensino, Smith e Naylor (2011) apresentam que, enquanto aproximadamente 37\% dos estudantes evadiram do ensino superior nos Estados Unidos, na Grã-Bretanha essa taxa ficou próxima dos $18 \%$. Ou seja, a evasão no ensino superior do país não é tão elevada quanto no caso norte-americano, mas ainda assim é significativa. A partir dessa informação os autores avaliam, por meio do uso de modelo binomial, a probabilidade que um indivíduo tinha de abandonar o curso, no começo da década de 1990. Alunos que melhor se integram ao ambiente universitário não estão propensos a evadir.

Além disso, o desemprego na região em que o estudante residia influencia de maneira positiva na decisão de abandonar a universidade, especialmente entre alunos mais pobres. Ishitani (2003), ao utilizar o método de Análise de Sobrevivência para avaliar a evasão de alunos que são os primeiros da sua família a frequentar a universidade nos Estados Unidos conclui que eles têm maiores chances de evadir em comparação aos estudantes com pais que possuem ensino superior.

Por fim, analisa-se o impacto da relação entre a situação socioeconômica e a evasão. Dessa forma, as políticas criadas para a concessão de benefícios para estudantes em vulnerabilidade social são apontadas como importantes ferramentas para diminuir o abandono do ensino superior. Nora (1990), ao analisar o caso de estudantes hispânicos no Texas, conclui que dificuldades financeiras são a principal razão pela qual os alunos abandonam o ensino superior.

Desjardins, Ahlburg e Mccall (1999) estudam quais as características dos indivíduos que influenciam no abandono na Universidade de Minessota, inclusive após considerar se são ou não contemplados com alguma forma de benefício para custear seus estudos. Ao analisar os programas de apoio financeiro, o autor conclui que, quanto mais recursos um aluno receber, menor é a chance de ocorrer a evasão. Bettinger (2004), ao analisar os efeitos dos Pell Grants nas taxas de retenção de alunos de universidades públicas de Ohio, por meio do método de Identificação de Painel, encontra que há relação significativa entre a quantidade de recursos disponibilizados e taxas de retenção.

Para o caso brasileiro, os trabalhos encontrados até o momento analisam o problema da evasão em instituições específicas. Para os cursos de Ciências Exatas e Tecnologia, Fregoneis (2002) avalia a evasão dos alunos dos cursos 
da Universidade Estadual de Maringá (UEM). Para essa situação, a autora aponta que um dos principais motivos para a evasão é a reprovação nas disciplinas. Esse evento pode levar o estudante a abandonar o curso. Além disso, foi encontrado um elevado índice de reprovações nos primeiros semestres dos cursos de Engenharia e Física.

Andriola et al. (2006) analisam a evasão na Universidade Federal do Ceará (UFC) pelo ponto de vista dos docentes, coordenadores e dos próprios evadidos. Segundo os próprios estudantes, dentre os principais motivos para o abandono estão o baixo conhecimento sobre o curso no momento da entrada; a baixa compatibilidade entre horários de estudo e trabalho; aspectos familiares (como é o caso da necessidade de cuidar dos filhos pequenos); e, finalmente, a inadequação curricular ou condições físicas precárias do curso.

Adachi (2011) analisa a evasão de estudantes da Universidade Federal de Minas Gerais (UFMG). Nos anos analisados, houve elevado abandono nas engenharias e em alguns cursos de física e matemática. Observou-se ainda que em relação aos cursos que tradicionalmente recebem estudantes com condições financeiras inferiores e aqueles que apresentam menor prestígio social, houve registro de maior índice de abandono. Além disso, o fraco desempenho do estudante nas disciplinas é outro motivo que tem impacto relevante na evasão. Para o caso específico do curso de matemática, além da influência do baixo rendimento, verificou-se que houve maior abandono nos cursos noturnos.

Lima Jr., Silveira e Ostermann (2012) analisam a evasão dos estudantes de licenciatura e bacharelado em física da Universidade Federal do Rio Grande do Sul (UFRGS) por meio do método de Análise de Sobrevivência. Os autores concluem que esse curso possui alta taxa de evasão - de aproximadamente $72,8 \%$ - sendo isso algo que ocorre em praticamente todos os cursos de física do país. A maior parte do abandono não acontece no início da graduação, ou seja, os alunos tendem a evadir após alguns anos. Em relação ao gênero, homens e mulheres têm a mesma propensão a desistir, com a diferença de que estas levam mais tempo para abandonar o curso. Além disso, quanto maior for a nota no vestibular, mais cedo os alunos tendem a se graduar. 
Silva (2013) analisa a evasão de estudantes da Fundação Escola de Comércio Álvares Penteado (FECAP) entre 2006 e 2009. Ao utilizar a metodologia de análise de sobrevivência, constatou que o aumento da idade, a elevação dos preços das mensalidades e as reprovações aumentavam as chances de o aluno abandonar o curso. Já a nota na disciplina de português no processo seletivo e o fato de o indivíduo ser contemplado com o PROUNI apresentaram efeitos negativos nas chances de evasão.

Por fim, Mendes Junior (2014) avalia a evasão de alunos cotistas da Universidade do Estado do Rio de Janeiro - primeira instituição de ensino superior do país a implementar o sistema de cotas. Entre os seus resultados, o autor aponta que esses estudantes apresentaram um Coeficiente de Rendimento pior ao longo do curso, quando comparados com alunos não cotistas. Porém, alunos contemplados com essa política de ação afirmativa apresentaram maiores taxas de graduação que os demais, indicativo de que esses alunos dão elevado valor aos cursos nos quais ingressam.

\section{Metodologia}

A Análise de Sobrevivência é uma ferramenta estatística popular em trabalhos na área da saúde, porém pouco utilizada em outras áreas, como é o caso das ciências sociais aplicadas. Quanto ao seu uso em estudos econômicos a respeito da evasão no ensino superior, pode-se mencionar alguns ensaios. Ishitani (2003) avalia o abandono do curso de graduação por parte de indivíduos que são os primeiros de suas famílias a ingressarem no ensino superior e DesJardins, Ahlburg e McCall (2002) analisam como mudanças nos programas de apoio financeiro impactam na decisão dos alunos de abandonar o curso ao longo do tempo. Radcliffe, Huesman e Kellogg (2006) estudam os motivos que levam à persistência e, consequentemente, à conclusão do curso, enquanto Murtaugh, Burns e Schuster (1999) avaliam a retenção na Universidade do Oregon, nos Estados Unidos.

Essa técnica busca analisar o tempo de sobrevivência $T$ dos indivíduos na amostra dentro de um período $t$. O evento que marca a saída do estudante, no caso deste artigo, é a evasão. O período $t$ é igual a seis, que corresponde à quantidade de anos que esse estudo compreende. Ao longo do tempo, as 
observações são classificadas como morte (death) ou perda (loss): a primeira ocorre quando o evento estudado acontece e a segunda corresponde ao indivíduo que sobreviveu além daquele período. As observações que sobrevivem além do período final do estudo, $t$, são denominadas observações censuradas. Tem-se que a função de distribuição cumulativa consiste na probabilidade de o indivíduo sobreviver por um tempo menor que $t$, que é representada por $\mathrm{F}(\mathrm{t})$. Já a função de sobrevivência é a probabilidade de se observar um tempo de vida igual ou maior que $t$, simbolizada por $\mathrm{S}(\mathrm{t})$ (Hosmer e Lameshow 1999). Essas duas funções podem ser representadas como:

$$
\begin{aligned}
& F(t)=\operatorname{Pr}(T<t) \\
& S(t)=\operatorname{Pr}(T \geq \mathrm{t})
\end{aligned}
$$

Existem diversos modelos que podem ser estimados para se realizar um estudo de Análise de Sobrevivência. Eles são divididos em não paramétricos, paramétricos e semi-paramétricos. Dentro da última categoria inclui-se o Modelo de Regressão de Cox, cujo pressuposto está na proporcionalidade das funções de risco, ou seja, a taxa de risco de morrer para dois indivíduos é a mesma, não importa quanto tempo eles sobrevivam. A função de risco, dado um conjunto de variáveis $\boldsymbol{x}=\left(x_{1}, x_{2}, \ldots, x_{p}\right)^{\prime}$ pode ser escrita como uma função de risco subjacente e uma função apenas de covariadas, representada por $g\left(x_{1}, \ldots, x_{p}\right)$ :

$$
\mathrm{h}(\mathrm{t} \mid \mathbf{x})=\mathrm{h}_{0}(\mathrm{t}) \mathrm{g}(\mathbf{x})
$$

O Modelo de Regressão de Cox assume que g(x) é uma função exponencial das covariadas, ou seja,

$$
g(x)=\exp \left(\Sigma b_{j} x_{j}\right)=\exp \left(\boldsymbol{b}^{\prime} \boldsymbol{x}\right)
$$

E a função de risco é:

$$
(t \mid \boldsymbol{x})=h_{0}(t) \exp \left(\Sigma b_{j} x_{j}\right)=h_{0}(t) \exp \left(\boldsymbol{b}^{\prime} \boldsymbol{x}\right)
$$


Em que $\boldsymbol{b}=\left(b_{1}, \ldots, b_{n}\right)$ representa os coeficientes das covariadas. Eles podem ser estimados a partir dos dados e indicar a magnitude dos efeitos de cada uma delas, enquanto que $\mathrm{g}(\mathrm{x})$ representa o efeito das covariadas. Por fim, $\mathrm{h}_{0}(\mathrm{t})$ indica o quanto o risco varia com o passar do tempo (Lee e Wang 2003).

É importante destacar que as técnicas não-paramétricas, embora sejam muito limitadas, são empregadas de forma exploratória para a investigação dos dados. Uma das ferramentas mais utilizadas para estimar a função de sobrevivência de uma amostra é o método de Kaplan-Meier. Publicado pela primeira vez em 1958, ele apresenta estimações a respeito da probabilidade de sobrevivência e a representação gráfica da sua distribuição. Ao reescrever os tempos de sobrevivência como $t_{1}, t_{2}, \ldots, t_{n}$, em ordem crescente, tem-se:

$$
t_{1} \leq t_{2} \leq \ldots \leq t_{n}
$$

Considera-se que $N$ é o total de indivíduos em que o tempo de sobrevivência, para observações censuradas ou não, está disponível; $r$ corresponde aos números inteiros positivos para os quais $t_{n} \leq t$ (Kaplan e Meier 1958). Para o caso de uma amostra que contenha dados censurados, a representação do estimador da função de Kaplan-Meier é definida como:

$$
S(t)=\Pi \frac{(N-r)}{(N-r+1)}
$$

As técnicas paramétricas têm a vantagem sobre as não paramétricas de inserir diversas covariadas na análise, além de poder testar a sua significância estatística. Lee e Wang (2003) sugerem a utilização de métodos não paramétricos como o primeiro passo da análise. Os resultados encontrados por meio dessas técnicas podem auxiliar na escolha da melhor distribuição, caso o pesquisador opte por um modelo em que seja necessário especificá-la. As distribuições mais utilizadas no método de Análise de Sobrevivência são a Exponencial, Gompertz, Loglogística, Lognormal e Weibull. 
Tabela 1 - Distribuições paramétricas e suas funções de sobrevivência

\begin{tabular}{|c|c|c|c|c|}
\hline Distribuição & Modelo & Função de Sobrevivência & Parametrização & Parâmetros Auxiliares ${ }^{4}$ \\
\hline Exponencial & $\mathrm{PH}$ & $\exp \left(-\lambda_{j} t_{j}\right)$ & $\lambda_{j}=\exp \left(x_{j} \beta\right)$ & \\
\hline Exponencial & AFT & $\exp \left(-\lambda_{j} t_{j}\right)$ & $\lambda_{j}=\exp \left(-x_{j} \beta\right)$ & \\
\hline Weibull & $\mathrm{PH}$ & $\exp \left(-\lambda_{j} t_{j}^{p}\right)$ & $\lambda_{j}=\exp \left(x_{j} \beta\right)$ & $p$ \\
\hline Weibull & AFT & $\exp \left(-\lambda_{j} t_{j}^{p}\right)$ & $\lambda_{j}=\exp \left(-p x_{j} \beta\right)$ & $p$ \\
\hline Gompertz & $\mathrm{PH}$ & $\exp \left\{\lambda_{j} \gamma^{-1}\left(e^{\gamma t_{j}}-1\right)\right\}$ & $\lambda_{j}=\exp \left(x_{j} \beta\right)$ & $\gamma$ \\
\hline Lognormal & AFT & $1-\Phi\{(\ln (\mathrm{t})-\mu) / \sigma\}$ & $\mu_{j}=x_{j} \beta$ & $\sigma$ \\
\hline Loglogística & AFT & $\left\{1+\left(\lambda_{j} t_{j}\right)^{\frac{1}{\gamma}}\right\}^{-1}$ & $\lambda_{j}=\exp \left(-x_{j} \beta\right)$ & $\gamma$ \\
\hline
\end{tabular}

Fonte: tabela elaborada a partir de Cameron e Trivedi (2005) e StataCorp (2013).

Além do gráfico de Kaplan-Meier, outra ferramenta utilizada para selecionar a distribuição mais adequada para o modelo consiste no Critério de Informação de Akaike. A partir dessa escolha, o modelo de análise de sobrevivência empregado pode variar. Os modelos de regressão com as distribuições Exponencial e Weibull podem ser implementados tanto por meio do modelo Accelerated Failure-Time (AFT) quanto do Proportional Hazards (PH). O modelo de regressão com a distribuição Gompertz pode ser aplicado apenas por meio do Proportional Hazards (PH), enquanto que modelos de regressão com as distribuições Lognormal e Loglogística são implementados por intermédio do Accelerated Failure-Time (AFT). As funções de sobrevivência para cada distribuição e modelo são apresentadas na Tabela 1.

Os modelos paramétricos Proportional Hazards (PH) e o Accelerated Failure- Time (AFT) são comumente utilizados para se analisar os efeitos das covariadas em funções de sobrevivência. O primeiro tem por característica a monotonicidade da sua Hazard Rate - ou ainda, taxa de riscos proporcionais - que pode ser expressa como:

${ }^{4}$ O Stata - software utilizado neste trabalho - oferece seis opções de modelos de regressões paramétricas para análise de sobrevivência: Exponencial, Weibull, Lognormal, Loglogistica, Gompertz e Gamma. Pode-se especificar o modelo e a distribuição que se deseja usar. Todos os modelos, com exceção do exponencial, possuem parâmetros auxiliares (ancillary parameters) que são estimados a partir dos dados. O padrão é que esses parâmetros auxiliares sejam tratados como constantes, mas pode-se modelar esses parâmetros como função de um estimador linear. 


$$
\theta\left(\mathrm{t}, \mathrm{X}_{i}\right)=\theta_{o}(t) \exp \left(\beta^{\prime} X_{i}\right)=\theta_{o}(t) \lambda
$$

Assume-se que $\theta_{o}(t)$ é a função de risco padrão, que depende de $t$, mas não de $X$, e que representa o padrão de dependência da duração, que assume ser igual para todos os indivíduos analisados. Além disso, $\lambda=\exp \left(\beta^{\prime} X\right)$ é uma função não negativa das covariadas de $X$, que dimensiona a função de risco padrão comum a todos os indivíduos (Jenkins 2005). Essa expressão apresenta taxa de riscos proporcionais no momento $t$ para o indivíduo $i$, que possui o vetor de covariadas $X_{i}$.

Para o modelo Accelerated Failure-Time (AFT), o logaritmo natural do tempo de sobrevivência, $\ln (\mathrm{T})$, é expresso como uma função linear das covariadas, onde $X_{j}$ é o vetor das covariadas, $\beta^{*{ }^{\prime}}$ é o vetor dos coeficientes da regressão e $\mathrm{z}_{\mathrm{j}}$ é o termo de erro:

$$
\ln (T)=\beta^{* \prime} X_{j}+z_{j}
$$

Uma das maneiras mais comuns para se interpretar os resultados do modelo é por meio do uso de Taxas de Tempo (Time Ratios) na estimação. A sua interpretação parte do pressuposto que o aumento de uma unidade em determinada variável, mantidas todas as demais constantes, provoca uma elevação no percentual do tempo de sobrevivência (Jenkins 2005). A Taxa de Tempo é definida como:

$$
e^{\beta_{k}}=\frac{T\left(X_{k}+1\right)}{T\left(X_{k}\right)}
$$

Esse modelo tem como propriedade indicar se o efeito de cada variável é o de reduzir ou aumentar o tempo de sobrevivência dos indivíduos em relação a determinado evento. No caso deste artigo, busca-se analisar se o impacto das variáveis selecionadas é positivo ou negativo sobre a evasão.

Para comparar a evasão das cinco amostras selecionadas, será feito uso de duas ferramentas de análise de sobrevivência: a não paramétrica e uma paramétrica. A primeira é o Teste de Kaplan-Meier, que facilita a visualização das taxas de sobrevivência desses grupos no ensino superior. A segunda etapa da análise consistirá na utilização de uma técnica paramétrica, através da aplicação do modelo de Accelerated Failure Time (AFT), que estima as Taxas de Tempo - ou relações temporais. 


\section{Fonte de Dados e Estatísticas Descritivas}

Para analisar as diferenças na evasão de estudantes de instituições privadas e públicas do ensino superior brasileiro, foram coletados dados nos Censos da Educação Superior de 2009 a 2014, disponibilizados pelo Instituto Nacional de Estudos e Pesquisas Educacionais Anísio Teixeira (INEP). Foram selecionados 237.697 estudantes que ingressaram no ano de 2009 em instituições privadas e públicas, de cursos de graduação presenciais de bacharelado nas áreas de Ciência, Matemática e Computação e Engenharia, Produção e Construção. Essa classificação ocorre a partir do método da OCDE, que separa os cursos por áreas de estudo. A primeira categoria concentra cursos como ciências biológicas, física e química, enquanto que a segunda é composta pelas engenharias e arquitetura.

Além do tipo de instituição, as duas categorias foram separadas pelo tempo de integralização do curso, que pode ser de quatro ou cinco anos. As licenciaturas não foram incluídas, pois estão na categoria da OCDE que é denominada Educação. Como todos os estudantes da amostra ingressaram no mesmo momento, não há observações com entrada depois do ano de 2010. Em função das diferenças no perfil dos estudantes de cursos presenciais e a distância, optou-se pela análise de apenas uma das categorias. Foram escolhidos alunos de cursos presenciais, uma vez que estes são a grande maioria nas áreas de estudo selecionadas.

O Censo da Educação Superior permite a obtenção de informações relacionadas ao estudante (idade, gênero e ano de ingresso), à instituição (presença de laboratório, biblioteca e infraestrutura para deficientes), ao curso (tempo de duração e turno das aulas) e aos docentes (qualificação dos professores). Não é permitido reconhecer a identidade do estudante por meio dos dados do Censo, contudo, é possível segui-lo ao longo do tempo através do código de identificação único do aluno. As variáveis utilizadas para a análise e a sua descrição são apresentadas na Tabela 2. 
Tabela 2 - Variáveis utilizadas e descrição

\begin{tabular}{|c|c|}
\hline Variável & Legenda \\
\hline FEMININO & 1 caso 0 aluno seja do sexo feminino, 0 caso contrário. \\
\hline IDADE & Idade dos alunos \\
\hline APOIO_MORADIA & 1 caso 0 aluno tenha recebido apoio moradia, 0 caso contrário. \\
\hline BOLSA_PERMANENCIA & 1 caso 0 aluno tenha recebido bolsa permanência, 0 caso contrário. \\
\hline PROUNI_PARCIAL & 1 caso o aluno tenha sido contemplado com PROUNI parcial, 0 caso contrário. \\
\hline PROUNI_INTEGRAL & 1 caso 0 aluno tenha sido contemplado com PROUNI integral, 0 caso contrário. \\
\hline FIES & 1 caso 0 aluno tenha sido contemplado com FIES, 0 caso contrário. \\
\hline PROUNI_PARCIAL_FIES & 1 caso 0 aluno tenha sido contemplado com PROUNI parcial e FIES, 0 caso contrário. \\
\hline AT_REMUNERADA & 1 caso 0 aluno exerça alguma atividade remunerada, 0 caso contrário. \\
\hline AT_N_REMUNERADA & 1 caso 0 aluno exerça alguma atividade não remunerada, 0 caso contrário. \\
\hline CONCORRIDO & $\begin{array}{l}1 \text { caso o curso tenha a mesma quantidade de vagas ofertadas e alunos matriculados no } \\
\text { primeiro ano, } 0 \text { caso contrário. }\end{array}$ \\
\hline OUT_INGRESSO & $\begin{array}{l}1 \text { caso o aluno tenha ingressado no curso de outra forma que não seja através do vestibular, } \\
0 \text { caso contrário. }\end{array}$ \\
\hline OCDE_4 & 1 caso o curso pertença à área "ciência, matemática e computação", conforme a OCDE. \\
\hline OCDE_5 & 1 caso o curso pertença à área "engenharia, produção e construção", conforme a OCDE. \\
\hline INTEGRAL & 1 caso o curso ofereça disciplinas em período integral, 0 caso contrário. \\
\hline NOTURNO & 1 caso o curso ofereça disciplinas no turno noturno, 0 caso contrário. \\
\hline LABORATORIO & $\begin{array}{l}1 \text { caso o curso demandasse e a instituição possuísse laboratório no ano de 2009, } 0 \text { caso } \\
\text { contrário. }\end{array}$ \\
\hline ACESSIBILIDADE & 1 caso a instituição tivesse infraestrutura adaptada no ano de 2009, 0 caso contrário. \\
\hline BIBLIOTECA & 1 caso a instituição tivesse biblioteca no ano de 2009, 0 caso contrário. \\
\hline SUL & 1 caso o curso esteja localizado na região sul, 0 caso contrário. \\
\hline NORTE & 1 caso 0 curso esteja localizado na região norte, 0 caso contrário. \\
\hline SUDESTE & 1 caso o curso esteja localizado na região sudeste, 0 caso contrário. \\
\hline NORDESTE & 1 caso o curso esteja localizado na região nordeste, 0 caso contrário. \\
\hline CENTRO_OESTE & 1 caso o curso esteja localizado na região centro-oeste, 0 caso contrário. \\
\hline PUBLICA & 1 caso a instituição seja pública, 0 caso contrário. \\
\hline
\end{tabular}

Fonte: tabela elaborada a partir de INEP (2009), INEP (2010a), INEP (2011), INEP (2012b), INEP (2013a) e INEP (2014a). 
Porém, deve-se ressaltar que essa base de dados apresenta algumas limitações. Uma delas refere-se à falta de variáveis que apresentem a condição socioeconômica do estudante. A fim de contornar essa situação, buscou-se variáveis proxies para tentar identificar a condição do indivíduo. O Censo da Educação Superior apresenta informações a respeito dos benefícios estudantis que os alunos recebem ao longo do curso. Dessa forma, escolheu-se como proxies o estudante ser contemplado com a Bolsa Permanência e o Apoio Moradia, para o caso das instituições públicas, e o recebimento do PROUNI Integral para as privadas.

A Bolsa Permanência consiste em benefício financeiro concedido a alunos em condição de vulnerabilidade socioeconômica, enquanto que o Apoio Moradia é um programa das instituições públicas que fornece moradia a estudantes de baixa renda oriundos de cidades diferentes de onde o seu curso é oferecido. Já o PROUNI Integral consiste em bolsas integrais concedidas a estudantes da rede privada, que tenham renda familiar per capita de até um salário mínimo e meio mensal.

\subsection{Estatísticas Descritivas}

Em primeiro lugar, avalia-se a quantidade de estudantes que continuaram, evadiram e se graduaram para cada ano, por tipo de instituição e duração do curso. Os evadidos estão divididos em três categorias: desvinculados, transferidos e outros. O grupo Outros refere-se aos indivíduos que abandonaram o curso, mas que não tem especificado o motivo. Nas instituições públicas, a maior evasão ocorreu em 2009 para os cursos de quatro e em 2010 para os de cinco anos. Quanto ao número de graduados, a quantidade mais expressiva não aparece no período mínimo para integralização do curso, mas no ano seguinte. 
Tabela 3 - Situação do Aluno em Instituições Públicas, 2009-2014

\begin{tabular}{|c|c|c|c|c|c|c|c|c|c|}
\hline \multicolumn{10}{|c|}{ Cursos de cinco anos } \\
\hline Ano & Total & Curs. & Tranc. & Form. & Desvinc. & Transf. & Outros & $\begin{array}{c}\% \\
\text { Evadido }\end{array}$ & $\begin{array}{c}\% \\
\text { Graduado }\end{array}$ \\
\hline 2009 & 37.674 & 33.007 & 1.035 & - & 1.698 & - & 1.932 & 9,63 & - \\
\hline 2010 & 32.746 & 26.420 & 1.654 & 154 & 3.313 & 199 & 1.063 & 12,14 & 0,40 \\
\hline 2011 & 28.745 & 24.393 & 1.429 & 159 & 2.335 & 239 & 189 & 7,33 & 0,42 \\
\hline 2012 & 24.841 & 20.387 & 1.606 & 442 & 1.799 & 214 & 391 & 6,38 & 1,17 \\
\hline 2013 & 22.072 & 15.904 & 845 & 3.689 & 1.209 & 124 & 217 & 4,11 & 9,79 \\
\hline 2014 & 17.041 & 9.164 & 684 & 6.095 & 1.039 & 58 & - & 2,91 & 16,17 \\
\hline \multicolumn{10}{|c|}{ Cursos de quatro anos } \\
\hline Ano & Total & Curs. & Tranc. & Form. & Desvinc. & Transf. & Outros & $\begin{array}{c}\% \\
\text { Evadido }\end{array}$ & $\begin{array}{c}\% \\
\text { Graduado }\end{array}$ \\
\hline 2009 & 27.897 & 19.441 & 789 & - & 1.364 & - & 6.302 & 27,47 & - \\
\hline 2010 & 18.795 & 14.196 & 1.308 & 154 & 2.084 & 256 & 788 & 11,21 & 0,55 \\
\hline 2011 & 15.614 & 12.024 & 983 & 161 & 1.891 & 237 & 317 & 8,76 & 0,57 \\
\hline 2012 & 12.900 & 8.543 & 974 & 1.668 & 1.437 & 108 & 170 & 6,14 & 4,18 \\
\hline 2013 & 9.610 & 5.324 & 701 & 2.423 & 953 & 84 & 123 & 4,16 & 8,68 \\
\hline 2014 & 6.147 & 3.027 & 535 & 1.768 & 774 & 42 & - & 2,92 & 6,33 \\
\hline
\end{tabular}

Fonte: elaboração própria a partir de INEP (2009), INEP (2010a), INEP (2011), INEP (2012), INEP (2013) e INEP (2014a).

${ }^{*}$ Curs.: Cursando; Tranc.: Trancados; Form.: Formados; Desvinc.: Desvinculados; Transf: Transferidos.

Ao serem comparadas as Tabelas 3 e 4, percebe-se que a maioria dos estudantes da amostra é oriunda de instituições privadas. Ao contrário das públicas, a maior evasão nas instituições privadas ocorreu em 2009 para as duas categorias de cursos. Em geral, as taxas de evasão se tornam menores à medida que os indivíduos permanecem no curso. Logo, conforme os semestres são completados, aumenta o custo de oportunidade para evadir.

Além disso, a maior proporção de estudantes graduados está no ano previsto para a conclusão: para os cursos de quatro anos, 10,46\% dos indivíduos que ingressaram em 2009 se formaram em 2012, enquanto que esse valor passou para 7,38\% em 2013. Nas graduações de cinco anos, 11,56\% concluíram o curso em 2013, sendo que em 2014, essa proporção foi de 8,83\%. De modo geral, a evasão é superior nas instituições privadas. Para os cursos de cinco anos, ela é menos expressiva nas públicas. 
Tabela 4 - Situação do Aluno em Instituições Privadas, 2009-2014

\begin{tabular}{|c|c|c|c|c|c|c|c|c|c|}
\hline \multicolumn{10}{|c|}{ Cursos de cinco anos } \\
\hline Ano & Total & Curs. & Tranc. & Form. & Desvinc & Transf. & Outros & $\begin{array}{c}\% \\
\text { Evadidos }\end{array}$ & $\begin{array}{c}\% \\
\text { Graduados }\end{array}$ \\
\hline 2009 & 105.159 & 75.779 & 7.032 & - & 12.300 & - & 10.036 & 21,24 & - \\
\hline 2010 & 82.867 & 52.533 & 9.653 & 603 & 14.989 & 2.187 & 2.896 & 19,08 & 0,57 \\
\hline 2011 & 62.520 & 42.952 & 7.474 & 910 & 8.605 & 1.350 & 1.223 & 10,62 & 0,86 \\
\hline 2012 & 52.578 & 36.566 & 6.242 & 1.720 & 6.396 & 794 & 857 & 7,65 & 1,63 \\
\hline 2013 & 43.359 & 21.585 & 4.133 & 12.172 & 4.329 & 416 & 718 & 5,19 & 11,56 \\
\hline 2014 & 25.833 & 10.365 & 2.961 & 9.275 & 3.035 & 194 & - & 3,07 & 8,83 \\
\hline \multicolumn{10}{|c|}{ Cursos de quatro anos } \\
\hline Ano & Total & Curs. & Tranc. & Form. & Desvinc & Transf. & Outros & $\begin{array}{c}\% \\
\text { Evadidos }\end{array}$ & $\begin{array}{c}\% \\
\text { Graduados }\end{array}$ \\
\hline 2009 & 66.967 & 43.922 & 5.152 & - & 8.112 & - & 9.769 & 26,70 & - \\
\hline 2010 & 46.905 & 27.573 & 6.584 & 704 & 9.319 & 1.160 & 1.559 & 17,97 & 1,05 \\
\hline 2011 & 34.224 & 22.204 & 4.848 & 885 & 5.314 & 549 & 420 & 9,38 & 1,32 \\
\hline 2012 & 27.740 & 12.038 & 3.764 & 6.979 & 4.084 & 416 & 452 & 7,39 & 10,46 \\
\hline 2013 & 15.896 & 5.300 & 2.664 & 4.946 & 2.627 & 157 & 201 & 4,45 & 7,38 \\
\hline 2014 & 8.060 & 2.510 & 1.951 & 1.849 & 1.656 & 92 & - & 2,61 & 2,91 \\
\hline
\end{tabular}

Fonte: elaboração própria a partir de INEP (2009), INEP (2010a), INEP (2011), INEP (2012), INEP (2013) e INEP (2014a).

*Curs.: cursando; Tranc.: Trancados; Form.: Formados; Desvinc.: Desvinculados; Transf: Transferidos.

Em seguida, analisam-se as estatísticas descritivas das variáveis que descrevem as características dos alunos, cursos e instituições públicas e privadas. As Tabelas 10 a 15, que apresentam esses resultados, estão no anexo. Para o caso dos estudantes, foram escolhidas variáveis que apresentam características pessoais, como idade e sexo, e outras que indicam a sua situação socioeconômica. Dentro desse último caso, estão as informações a respeito da concessão de bolsa permanência e apoio moradia nas instituições públicas e do FIES e PROUNI nas privadas. Também é analisado se o indivíduo participa de atividades não remuneradas e remuneradas, que são compostas por projetos de pesquisa e extensão, monitorias e estágios não obrigatórios. Percebe-se que essas áreas de estudo apresentam uma forte presença de homens, que correspondem a aproximadamente $70 \%$ da amostra.

Quanto à idade, os alunos das instituições públicas são mais novos que os das privadas, enquanto que os de cursos de quatro anos são mais velhos em comparação aos de cinco anos, independente do tipo de instituição. No que se refere à concessão dos benefícios de apoio moradia e bolsa permanência, não existe uma diferença expressiva entre os quatro grupos, porém, 
quando ela aparece, os matriculados em cursos de cinco anos são menos beneficiados. Nas privadas, as duas categorias foram mais contempladas com o PROUNI do que com o FIES. Dentre os que receberam o FIES, a sua concessão foi maior para os alunos dos cursos de cinco anos. As atividades não remuneradas são mais frequentes do que as remuneradas para três das quatro categorias no primeiro ano. Nas privadas, elas continuam a ter papel predominante ao longo do tempo, enquanto que nas públicas, as remuneradas se sobressaem.

Quanto às estatísticas descritivas das variáveis relacionadas ao curso, verifica-se que a área de Engenharia, Produção e Construção é, em sua grande maioria - entre $85 \%$ e $98 \%$ - composta por cursos com cinco anos de duração, enquanto que a área de Ciência, Matemática e Computação corresponde a grande maioria das graduações de quatro anos. A oferta de cursos com aulas noturnas é muito mais elevada nas privadas, enquanto que os de turno integral são mais oferecidos nas públicas. Além disso, foi criada uma variável para analisar se os cursos com um processo seletivo mais concorrido possuem maior evasão: os que tinham menos alunos matriculados do que a quantidade de vagas ofertadas em 2009 foram considerados cursos com baixa procura. A sobra de vagas pode ser um indicativo de que a procura por aquela graduação é baixa.

As variáveis para laboratório, acessibilidade e biblioteca foram selecionadas para analisar a infraestrutura dos locais em que os cursos são ofertados. Pelos valores elevados, a grande maioria delas possui esses itens. As variáveis sul, norte, nordeste, sudeste e centro-oeste foram utilizadas para avaliar onde os estudantes estão matriculados. A maior concentração ocorre na região sudeste e em seguida, aparecem as regiões sul e nordeste. No caso dos cursos de cinco anos em instituições públicas, o sul tinha a segunda maior parcela de indivíduos no começo da amostra. A partir de 2011, esse quadro se reverte e o nordeste passa a contar com um valor superior.

\section{Resultados}

Nesta seção, a sobrevivência no ensino superior dos estudantes presentes nas cinco amostras selecionadas será analisada a partir do emprego de duas ferramentas. A primeira é o Estimador de Kaplan-Meier. A Figura 1 mostra 
a taxa de sobrevivência média dos grupos para cada período. Percebe-se que a evasão média é elevada, sendo que apenas no primeiro ano, ela é de aproximadamente $25 \%$. Presume-se que esse fenômeno pode ocorrer devido à expectativa, muitas vezes diferente da realidade, que os estudantes tinham antes de entrar no curso e também à sua preparação ainda nos ensinos fundamental e médio.

O maior abandono do curso durante o primeiro ano foi encontrado também por Santelices et al. (2016), que mostraram esse mesmo fenômeno para o ensino superior chileno e por Fregoneis (2002), que apontou um elevado abandono dos estudantes dos cursos de engenharia e física da UEM. Porém, com o passar do tempo, a evasão decresce. No final do período de seis anos, a taxa de sobrevivência é inferior a 50\%. Fregoneis (2002) e Chen e Soldner (2013) afirmam que o mau desempenho no começo do curso pode influenciar na decisão do abandono.

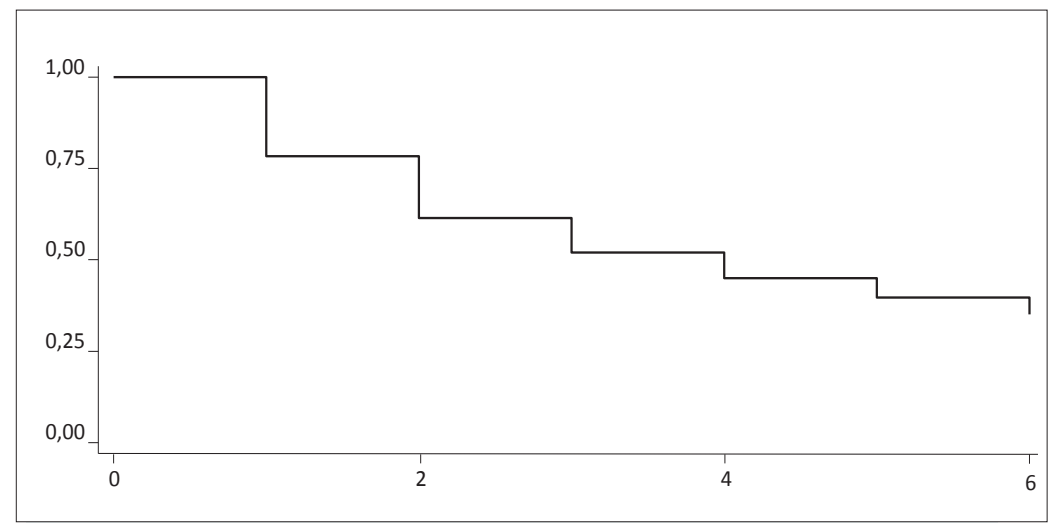

Figura 1 - Taxa de sobrevivência média para toda a amostra, mensurada pelo Estimador de Kaplan-Meier

Fonte: resultados estimados a partir de INEP (2009), INEP (2010a), INEP (2011), INEP (2012), INEP (2013) e INEP (2014a).

Para avaliar se as curvas de sobrevivência apresentadas a seguir são diferentes entre si de forma estatisticamente significante, pode-se realizar três testes: o de Logrank, Breslow e o de Tarone-Ware. O teste consiste na atribuição de pesos de forma a dar ênfase para diferenças no final, no começo e em fases intermediárias, respectivamente, do tempo de vida. $\mathrm{Ou}$ seja, são realizados esses três testes para discriminar melhor as curvas em 
determinadas fases da sua evolução. Todos os testes têm por hipótese nula a inexistência de diferença (Lima Jr., Silveira e Ostermann 2012).

Eles foram realizados para as variáveis de tempo de duração de curso e categoria administrativa da instituição. Conforme demonstrado na Tabela 5 , não foram encontradas diferenças estatisticamente significativas entre as curvas de evasão dos cursos de quatro anos nas públicas e de cinco nas privadas, para o meio e o final do tempo de vida. Para o começo do tempo de vida, elas são diferentes ao nível de significância de $1 \%$. Para as demais combinações, como todos os $p$-valores são iguais a zero, rejeita-se a hipótese nula e pode-se afirmar que as curvas são estatisticamente diferentes ao nível de significância de $1 \%$.

Tabela 5 - Testes de Significância Estatística

\begin{tabular}{|c|c|c|c|c|c|c|}
\hline & \multicolumn{2}{|c|}{ Teste de Breslow } & \multicolumn{2}{|c|}{ Teste de Tarone-ware } & \multicolumn{2}{|c|}{ Teste de Log-rank } \\
\hline & $\chi^{2}$ & Significância & $\chi^{2}$ & Significância & $x^{2}$ & Significância \\
\hline $\begin{array}{l}\text { Pública de cinco anos e } \\
\text { pública de quatro anos }\end{array}$ & $3.766,12$ & 0,000 & $3.617,46$ & 0,000 & $3.387,29$ & 0,000 \\
\hline $\begin{array}{l}\text { Pública de cinco anos e } \\
\text { privada de cinco anos }\end{array}$ & $5.710,63$ & 0,000 & $5.866,34$ & 0,000 & $5.814,77$ & 0,000 \\
\hline $\begin{array}{l}\text { Pública de cinco anos e } \\
\text { privada de quatro anos }\end{array}$ & $8.423,69$ & 0,000 & $8.945,62$ & 0,000 & $9.295,87$ & 0,000 \\
\hline $\begin{array}{l}\text { Pública de quatro anos e } \\
\text { privada de cinco anos }\end{array}$ & 18,37 & 0,000 & 2,61 & 0,106 & 0,87 & 0,349 \\
\hline $\begin{array}{l}\text { Pública de quatro anos e } \\
\text { privada de quatro anos }\end{array}$ & 220,27 & 0,000 & 363,59 & 0,000 & 564,40 & 0,000 \\
\hline $\begin{array}{l}\text { Privada de cinco anos e } \\
\text { privada de quatro anos }\end{array}$ & 899,96 & 0,000 & 979,52 & 0,000 & $1.091,49$ & 0,000 \\
\hline
\end{tabular}

Fonte: resultados estimados a partir de INEP (2009), INEP (2010a), INEP (2011), INEP (2012), INEP (2013) e INEP (2014a).

Ao comparar a evasão de alunos de instituições públicas e privadas de cursos com quatro e cinco anos de duração por meio do estimador de Kaplan-Meier, analisam-se as curvas de sobrevivência de quatro grupos diferentes. Conforme pode ser observado na Figura 2, a evasão dos estudantes é superior a 50\% ao final do período, com a exceção dos cursos de cinco anos em instituições públicas, que tiveram uma taxa de sobrevivência 
de aproximadamente $65 \%$ ao término da análise, índice semelhante ao apresentado por Smith e Naylor (2011) para a evasão no ensino superior norte-americano.

Para o começo do período, os cursos que tiveram o maior abandono foram os de quatro anos para os dois tipos de instituição, enquanto que ao final, a maior evasão se concentrou nas privadas. Esse fenômeno pode estar relacionado ao custo de entrada e à qualidade das instituições. Para o primeiro caso, os processos seletivos para ingresso nas públicas é mais concorrido, o que eleva o custo de oportunidade do abandono. Quanto à qualidade, a partir dos resultados do Índice Geral de Cursos (IGC) de 2014, calculou-se a média desse indicador para as públicas e privadas. Enquanto as públicas obtiveram uma média de 2,68 , as demais alcançaram um valor de 2,51 (INEP, 2014b). Esse resultado está correlacionado com o modelo apresentado por St. Johns et al. (2000), em que a persistência está relacionada com os custos e benefícios estimados pelos estudantes de estar matriculado em determinada universidade.

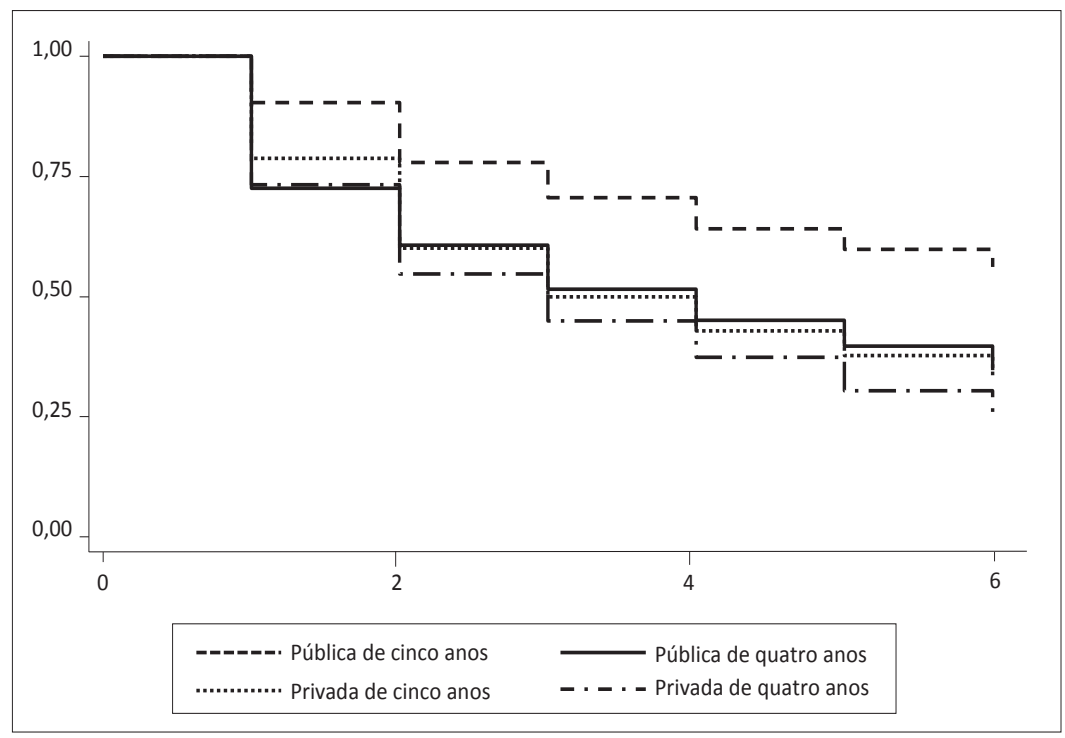

Figura 2 - Estimador de Sobrevivência de Kaplan-Meier, separado por grupos

Fonte: resultados estimados a partir de INEP (2009), INEP (2010a), INEP (2011), INEP (2012), INEP (2013) e INEP (2014a). 
Como mencionado na seção da metodologia, depois da análise do Estimador de Kaplan-Meier, emprega-se um dos modelos paramétricos, o Accelerated Failure Time (AFT) ou o Proportional Hazards (PH). De forma a melhor escolher qual deve ser utilizado, precisa-se, em primeiro lugar, analisar a distribuição de vida apresentada pelo gráfico de KaplanMeier. Percebe-se que ela é não monotônica, apresentando probabilidade maior para a ocorrência da evasão no início dos anos de estudo e menor à medida que o estudante avança na faculdade, o que condiz com as características das distribuições Lognormal e Loglogística. Ainda por esse método, excluem-se as distribuições Exponencial, Weibull e Gompertz, pois elas possuem uma função de taxa de falha monotônica.

Além de não ser monotônica, percebe-se que as taxas de evasão são diferentes entre as amostras. Em função das taxas se modificarem ao longo da graduação, não se pode estimar um modelo de riscos proporcionais - que se daria através do emprego do modelo semi-paramétrico do Modelo de Cox. Dessa forma, estimou-se um modelo de aceleração. Consequentemente, o modelo escolhido foi o Accelerated Failure Time (AFT).

Além da análise gráfica, o modelo AFT foi estimado com todas as distribuições mencionadas anteriormente. Para a escolha da melhor opção, foi analisado o Critério de Informação de Akaike. Nesse caso, optou-se pela distribuição lognormal, que apresentou o menor valor para os modelos estimados, conforme pode ser observado na Tabela 6 .

Tabela 6 - Critério de Informação de Akaike

\begin{tabular}{l|c|c|c}
\hline & Modelo Geral & $\begin{array}{c}\text { Cursos de quatro anos (ordenado em } \\
\text { públicas e privadas) }\end{array}$ & $\begin{array}{c}\text { Cursos de cinco anos (ordenado em } \\
\text { públicas e privadas) }\end{array}$ \\
\hline Exponencial & $559.179,0$ & $65.700,97$ & $73.398,67$ \\
Gompertz & $555.235,0$ & $65.482,44$ & $72.904,87$ \\
Lognormal & 519.047 .4 & $60.864,52$ & $69.187,79$ \\
Loglogística & $527.924,0$ & $61.952,16$ & $70.222,88$ \\
Weibull & $559.142,4$ & $63.897,00$ & $71.356,82$ \\
\hline
\end{tabular}

Fonte: resultados estimados a partir de INEP (2009), INEP (2010a), INEP (2011), INEP (2012), INEP (2013) e INEP (2014a). 
É importante ressaltar que os modelos utilizados na estimação permitem apenas inferir os fatores associados à evasão no ensino superior. Os resultados obtidos pela Análise de Sobrevivência não permitem concluir pela existência de uma relação de causalidade entre a variável dependente e as variáveis explicativas. Caso fosse esse o objetivo, seria necessário empregar outras técnicas econométricas para controlar os problemas de variáveis omitidas - exemplos desse caso são a nota no vestibular e renda familiar dos estudantes, informações que não constam na base utilizada - erro de medida e simultaneidade, que porventura podem existir nas relações analisadas, e que não são tratados pelo método de Análise de Sobrevivência.

A partir dessas considerações, são apresentados na Tabela 7 os resultados do modelo AFT para toda a amostra e segregados pelo tipo da instituição e tempo de duração do curso. Para o modelo geral, caso o estudante seja do sexo feminino, o seu tempo de sobrevivência é 1,056 vezes maior do que dos homens. Para os cursos de cinco anos nas instituições privadas e públicas, o tempo de sobrevivência aumenta em 1,128 e 1,050 vezes, respectivamente. Porém, para os cursos de quatro anos em instituições públicas, a Time Ratio é de 0,962 , o que indica que o tempo de sobrevivência das mulheres é menor do que dos homens.

O fato de a mulher ser mais persistente no ensino superior - resultado encontrado para quatro das cinco regressões - é condizente com parte significativa da literatura sobre a evasão nesse nível educacional. Bound, Lovenheim e Turner (2009), ao analisar a expansão do ensino superior nos Estados Unidos, mostram que as mulheres evadiram menos. Para o caso chileno, Santelices et al. (2016) afirmam que elas são mais persistentes. Porém, Felder et al. (1993), ao analisar apenas o gênero como fator determinante para o abandono, não encontraram taxas significativas entre os dois grupos. Ao estudar a evasão em uma instituição privada brasileira, Silva (2011) encontrou o resultado oposto: as mulheres persistiram menos do que os homens. No que se refere à idade, de forma geral, quanto mais velhos forem os estudantes, menor é a sua taxa de sobrevivência. Esse resultado condiz com o de Murtaugh, Burns e Schuster (1999) e com Silva (2011).

Em seguida, analisam-se os benefícios estudantis para estudantes em condição de vulnerabilidade socioeconômica. Nesse caso, a análise dos resultados é realizada em comparação com os alunos que não receberam o benefício em questão. O resultado geral é que a maioria dos programas de 
apoio possui um impacto negativo na evasão. Um dos motivos que pode explicar isso são as mudanças promovidas no ensino superior desde o final da década de 1990. Com a expansão desse sistema de ensino, alunos de diferentes condições socioeconômicas passaram a ter acesso a esse nível de educação. No momento em que se oferece alguma forma de apoio para alunos que enfrentam maiores dificuldades financeiras, esses indivíduos tendem a abandonar menos os cursos. Nas instituições públicas, a bolsa permanência e o apoio moradia apresentaram resultados significativos, com a exceção do auxílio moradia para alunos dos cursos de quatro anos.

No modelo geral, os alunos contemplados com a Bolsa Permanência têm o seu tempo de sobrevivência elevado em 1,751 vezes, quando comparado com aqueles que não são beneficiários. Para o caso dos estudantes matriculados em cursos de cinco anos, o tempo de sobrevivência é 1,878 maior. Para o caso norte-americano, Murdock (1989) mostra que programas de apoio financeiro ajudam a reduzir barreiras socioeconômicas dentro das instituições. Dessa forma, indivíduos oriundos de famílias com condições financeiras inferiores conseguem se manter durante os anos do curso de graduação. Para o caso brasileiro, Adachi (2009) aponta que os cursos com maior evasão na UFMG foram os que apresentavam uma maior proporção com estudantes em pior situação financeira.

Para as instituições privadas, o estudante beneficiário do PROUNI integral tem um maior tempo de vida para todos os casos, enquanto que os contemplados com o PROUNI parcial apresentam uma taxa de sobrevivência negativa para duas das três estimações. Os resultados apresentados até aqui sobre programas de apoio estudantil são condizentes com a literatura sobre o tema: os beneficiários tendem a evadir menos. Esses dois resultados podem ser observados em Nora (1990), que mostra que quanto maior a quantidade de auxílio financeiro que o estudante receber, menor é a sua chance de evadir, já que na maioria das vezes, a maior dificuldade desses indivíduos está relacionada a questões financeiras. Silva (2011), ao analisar o caso da FECAP, mostra que alunos contemplados com o PROUNI tinham menores chances de evadir. Por fim, o resultado para os alunos que receberam o PROUNI parcial e o FIES não apresentaram significância estatística no modelo geral.

As atividades remuneradas e não remuneradas consistem em estágios não obrigatórios, monitorias, projetos de extensão e iniciação científica que o estudante participa durante a realização do curso superior. A participação 
nesse tipo de atividade reduz a chance de o estudante evadir consideravelmente: para o modelo geral, os alunos que têm uma atividade remunerada apresentam um tempo de sobrevivência 2,630 maior em comparação àqueles que não possuem, enquanto que para a atividade não remunerada esse valor é de 1,439. Acredita-se que esse resultado ocorra devido à maior integração do aluno com o ambiente escolar. Smith e Naylor (2011) confirmam essa hipótese ao afirmar que trabalhar no campus tem um efeito de integração social, ou seja, alunos que prestam serviços na sua instituição criam laços maiores com a comunidade escolar, o que tem um efeito negativo na evasão.

Tabela 7 - Accelerated Failure Time (AFT)- Características dos estudantes

\begin{tabular}{|c|c|c|c|c|c|}
\hline & \multirow{2}{*}{ Modelo Geral } & \multicolumn{2}{|c|}{ Curso de quatro anos } & \multicolumn{2}{|c|}{ Curso de cinco anos } \\
\hline & & Privada & Pública & Privada & Pública \\
\hline \multirow{2}{*}{ FEMININO } & $1,056^{* \star *}$ & 1,010 & $0,962^{* * *}$ & $1,128^{* * *}$ & $1,050^{* * *}$ \\
\hline & $(0,005)$ & $(0,007)$ & $(0,012)$ & $(0,007)$ & $(0,013)$ \\
\hline \multirow{2}{*}{ IDADE } & $0,997^{\star \star *}$ & 0,999 & $0,997^{\star *}$ & $0,997^{\star \star \star}$ & $0,992^{* \star *}$ \\
\hline & $(0,0003)$ & $(0,0006)$ & $(0,001)$ & $(0,000)$ & $(0,001)$ \\
\hline \multirow{2}{*}{ APOIO_MORADIA } & $1,230^{\star \star *}$ & 1 & $1,155^{\star * *}$ & 1 & $1,220^{* * *}$ \\
\hline & $(0,042)$ & (omitido) & $(0,062)$ & (omitido) & $(0,063)$ \\
\hline \multirow{2}{*}{ BOLSA_PERMANENCIA } & $1,751^{\star \star \star}$ & 1 & $1,731^{* * *}$ & 1 & $1,878^{\star * *}$ \\
\hline & $(0,075)$ & (omitido) & $(0,111)$ & (omitido) & $(0,129)$ \\
\hline \multirow{2}{*}{ PROUNI_PARCIAL } & $0,869^{* * *}$ & $1,108^{\star \star \star}$ & 1 & $0,728^{\star \star *}$ & 1 \\
\hline & $(0,014)$ & $(0,025)$ & (omitido) & $(0,014)$ & (omitido) \\
\hline \multirow{2}{*}{ PROUNI_INTEGRAL } & $1,515^{\star \star *}$ & $1,500^{\star \star *}$ & 1 & $1,503^{\star \star \star}$ & 1 \\
\hline & $(0,017)$ & $(0,025)$ & (omitido) & $(0,021)$ & (omitido) \\
\hline \multirow{2}{*}{ FIES } & $1,984^{\star \star *}$ & $1,896^{* * *}$ & 1 & $2,004^{* \star *}$ & 1 \\
\hline & $(0,031)$ & $(0,055)$ & (omitido) & $(0,035)$ & (omitido) \\
\hline \multirow{2}{*}{ PROUNI_PARCIAL_FIES } & 0,958 & $0,738^{\star \star *}$ & 1 & $1,181^{* *}$ & 1 \\
\hline & $(0,064)$ & $(0,075)$ & (omitido) & $(0,096)$ & (omitido) \\
\hline \multirow{2}{*}{ AT_REMUNERADA } & $2,630^{* * *}$ & $2,009^{\star \star \star}$ & $2,460^{\star \star \star}$ & $3,181^{* * *}$ & $2,644^{* * *}$ \\
\hline & $(0,031)$ & $(0,043)$ & $(0,074)$ & $(0,060)$ & $(0,082)$ \\
\hline \multirow{2}{*}{ AT_N_REMUNERADA } & $1,439^{\star \star *}$ & $1,373^{* * *}$ & $1,761^{\star \star \star}$ & $1,394^{* \star *}$ & $2,151^{* * *}$ \\
\hline & $(0,012)$ & $(0,016)$ & $(0,067)$ & $(0,016)$ & $(0,079)$ \\
\hline
\end{tabular}

Fonte: resultados estimados a partir de INEP (2009), INEP (2010a), INEP (2011), INEP (2012), INEP (2013) e INEP (2014a). Desvio padrão entre parênteses. ${ }^{* *}$ p-valor inferior ao nível de significância de $0,05,{ }^{* * *}$ p-valor inferior ao nível de significância de 0,01 . 
Ao analisar as características dos cursos, percebe-se que o tempo de sobrevivência nos de quatro anos é menor que nos de cinco anos. A variável correspondente a outras formas de ingresso no ensino superior indica se a entrada do indivíduo nesse nível de ensino se deu a partir da participação em um programa de ingresso seriado, alguma forma de processo interno, ou ainda, outras formas não especificadas. A variável que representa as outras formas de ingresso tem por categoria omitida os alunos que entraram nos cursos através dos concursos vestibulares específicos que cada universidade possuía naquele momento e que utilizaram o ENEM na sua nota do vestibular.

Alguns exemplos dessa forma de ingresso seriado são o Programa Seriado de Ingresso na Universidade (PSIU), da Universidade Federal do Piauí (UFPI) e o Programa de Avaliação Seriada para o Ensino Superior (PASES), da Universidade Federal de Viçosa (UFV). Percebe-se que ela se mostrou expressiva para os cursos de cinco anos de instituições públicas, que são as detentoras da grande maioria desses programas. Nesse caso, o aluno que ingressou por esse sistema apresenta um tempo de sobrevivência 1,143 vezes maior do que aqueles que prestaram o vestibular.

Ainda no que se refere à forma de ingresso, analisou-se o caso dos estudantes que prestaram o Exame Nacional do Ensino Médio (ENEM) para auxiliar no ingresso. Os resultados indicam que alunos que utilizaram a nota do ENEM possuem um tempo de sobrevivência maior do que a sua categoria omitida - no caso, alunos que entraram no curso através do vestibular ou de outras formas já mencionadas - quando há significância estatística. Esse resultado se confirmou para o modelo geral e para os cursos de quatro anos de instituições privadas e públicas.

Quanto ao tipo de curso, observa-se que, para todos os modelos estimados o tempo de vida é inferior para aqueles que estão na área de Ciência, Matemática e Computação se comparado aos de Engenharia, Produção e Construção. Um dos motivos que poderia explicar esse fenômeno são as diferentes remunerações que essas áreas pagam: enquanto a primeira área é composta por uma quantidade expressiva de cursos de licenciatura, que tradicionalmente possuem salários menores, a segunda tem carreiras como arquitetura, que possui melhor prospecção de rendimentos para o futuro. Já Adachi (2011) mostra que os cursos que apresentaram menor prestígio social possuem índices maiores de abandono. Quanto ao turno, os alunos do período noturno têm uma taxa de sobrevivência negativa, enquanto que 
a dos cursos integrais é positiva. Esses fatores podem estar relacionados, pois o número de cursos de cinco anos que são ofertados em tempo integral é maior em comparação aos demais. Além disso, os estudantes dos cursos noturnos são mais velhos.

De acordo com DesJardins, Ahlburg e McCall (1999), pessoas mais velhas têm tendência a apresentar maior dificuldade de se adaptar a carreiras acadêmicas devido à elevada probabilidade de elas trabalharem em tempo integral, e/ou poderem ser casados/casadas e consequentemente, terem outros compromissos e prioridades. Para o caso da Universidade Federal do Ceará, Andriola et al. (2006) indicam que os próprios estudantes evadidos da instituição afirmaram que as dificuldades de conciliar os horários do trabalho e das aulas, além de questões familiares - como a necessidade de cuidar dos filhos - foram fatores que influenciaram na decisão de abandonar o curso.

De forma geral, o tempo de sobrevivência dos estudantes dos cursos que apresentaram a mesma quantidade de matriculados no primeiro ano com o de vagas ofertadas naquele processo seletivo - definidos pela variável CONCORRIDO - é maior. A exceção ocorre nos cursos de quatro anos das instituições privadas. Para esse caso, Bean e Bradley (1986) mostram que nos cursos em que a concorrência entre os estudantes é elevada e os mesmos apresentam uma baixa satisfação, o desempenho acadêmico dos indivíduos é menor. Como apontado por Murtaugh, Burns e Schuster (1999) e Stinebrickner e Stinebrickner (2013b), alunos com menores notas tendem a apresentar maiores taxas de evasão. Além disso, Fregoneis (2002) e Adachi (2011) apontam o baixo desempenho dos estudantes como um dos motivos que influencia na decisão de evadir. 
Tabela 8 - Accelerated Failure Time-Características dos cursos

\begin{tabular}{|c|c|c|c|c|c|}
\hline & \multirow{2}{*}{ Modelo Geral } & \multicolumn{2}{|c|}{ Curso de quatro anos } & \multicolumn{2}{|c|}{ Curso de cinco anos } \\
\hline & & Privada & Pública & Privada & Pública \\
\hline \multirow{2}{*}{ NOTURNO } & $0,906^{\star \star \star}$ & 1,015 & $0,724^{\star \star \star}$ & $0,913^{\star \star *}$ & $1,059^{* \star *}$ \\
\hline & $(0,006)$ & $(0,014)$ & $(0,011)$ & $(0,009)$ & $(0,018)$ \\
\hline \multirow{2}{*}{ INTEGRAL } & $1,152^{\star \star \star}$ & 0,982 & $0,959^{* * *}$ & $1,028^{\star *}$ & $1,594^{\star \star \star}$ \\
\hline & $(0,008)$ & $(0,019)$ & $(0,014)$ & $(0,012)$ & $(0,023)$ \\
\hline \multirow{2}{*}{ OUTRO_INGRESSO } & $1,072^{\star \star \star}$ & 1,083 & 0,901 & $1,113^{\star \star *}$ & $0,902^{* * *}$ \\
\hline & $(0,006)$ & $(0,008)$ & $(0,0165)$ & $(0,008)$ & $(0,017)$ \\
\hline \multirow{2}{*}{ INGRESSO_ENEM ${ }^{5}$} & $1,022^{\star \star *}$ & $1,060^{* * *}$ & $1,408^{\star * *}$ & 0,992 & 1,023 \\
\hline & $(0,006)$ & $(0,011)$ & $(0,042)$ & $(0,008)$ & $(0,032)$ \\
\hline \multirow{2}{*}{ OCDE_4 } & $0,730^{* * *}$ & $0,800^{* * *}$ & $0,648^{\star \star *}$ & $0,698^{\star \star *}$ & $0,621^{\star \star *}$ \\
\hline & $(0,003)$ & $(0,009)$ & $(0,012)$ & $(0,016)$ & $(0,011)$ \\
\hline \multirow{2}{*}{ OCDE_5 } & 1 & 1 & 1 & 1 & 1 \\
\hline & (omitido) & (omitido) & (omitido) & (omitido) & (omitido) \\
\hline \multirow{2}{*}{ CONCORRIDO } & $1,179^{\star \star \star}$ & $0,938^{\star \star}$ & $1,449^{* \star *}$ & $1,183^{\star \star *}$ & $1,062^{* \star *}$ \\
\hline & $(0,013)$ & $(0,023)$ & $(0,030)$ & $(0,044)$ & $(0,022)$ \\
\hline
\end{tabular}

Fonte: resultados estimados a partir de INEP (2009), INEP (2010a), INEP (2011), INEP (2012), INEP (2013) e INEP (2014a). Desvio padrão entre parênteses. ${ }^{*}$ p-valor inferior ao nível de significância de $0,05,{ }^{* * *}$ p-valor inferior ao nível de significância de 0,01 .

A partir das características das instituições, percebe-se que a sobrevivência dos estudantes das públicas é 1,225 vezes maior em relação aos das privadas. Quanto à infraestrutura, as categorias omitidas são as instituições que não contam com o equipamento que está sendo estudado. Pelo modelo geral, alunos matriculados em universidades com laboratório elou condições de acessibilidade apresentam maior tempo de sobrevivência. Esse resultado é similar ao encontrado por Andriola et al (2006), que afirmam que uma das questões que influencia na decisão do aluno em abandonar o curso são as más condições físicas do curso. De forma geral, o tempo de sobrevivência diminui para todas as regiões se comparadas com a centro-oeste - a categoria omitida, para a análise das regiões - com exceção da nordeste. Ou seja, os alunos dessa região evadem menos que os demais.

5 A amostra desse trabalho é composta somente por estudantes que ingressaram no ano de 2009. Nesse ano, o ENEM foi utilizado como parte do processo seletivo por aproximadamente 500 instituições. Algumas atribuíram pesos para a nota desse exame que somavam pontos a nota do vestibular, enquanto que especificamente para o caso das privadas, O ENEM era indispensável para se obter uma bolsa pelo PROUNI (INEP 2008). 
Tabela 9 - Accelerated Failure Time (AFT) - Características das instituições

\begin{tabular}{|c|c|c|c|c|c|}
\hline & \multirow{2}{*}{ Modelo Geral } & \multicolumn{2}{|c|}{ Curso de quatro anos } & \multicolumn{2}{|c|}{ Curso de cinco anos } \\
\hline & & Privada & Pública & Privada & Pública \\
\hline \multirow{2}{*}{ LABORATORIO } & $1,044^{* \star *}$ & $1,210^{\star \star *}$ & $0,918^{\star \star \star}$ & $1,707^{* \star *}$ & $0,954^{* *}$ \\
\hline & $(0,012)$ & $(0,047)$ & $(0,016)$ & $(0,052)$ & $(0,022)$ \\
\hline \multirow{2}{*}{ ACESSIBILIDADE } & 1,010 & $0,763^{\star * *}$ & $1,174^{\star \star *}$ & $1,346^{* * *}$ & $1,055^{*}$ \\
\hline & $(0,015)$ & $(0,034)$ & $(0,030)$ & $(0,060)$ & $(0,029)$ \\
\hline \multirow{2}{*}{ BIBLIOTECA } & $0,860^{\star \star \star}$ & $0,708^{\star \star \star}$ & $1,223^{\star \star *}$ & $0,696^{* \star *}$ & $0,634^{\star \star *}$ \\
\hline & $(0,012)$ & $(0,018)$ & $(0,032)$ & $(0,017)$ & $(0,032)$ \\
\hline \multirow{2}{*}{ SUL } & $0,926^{\star \star \star}$ & 1,014 & $0,802^{* \star \star}$ & $1,088^{\star \star \star}$ & $0,716^{* \star *}$ \\
\hline & $(0,008)$ & $(0,015)$ & $(0,019)$ & $(0,016)$ & $(0,024)$ \\
\hline \multirow{2}{*}{ NORTE } & $0,827^{\star \star \star}$ & $0,776^{* \star *}$ & 0,989 & $0,738^{\star \star \star}$ & 0,970 \\
\hline & $(0,010)$ & $(0,015)$ & $(0,032)$ & $(0,014)$ & $(0,040)$ \\
\hline \multirow{2}{*}{ SUDESTE } & $0,854^{\star \star *}$ & $0,843^{\star * *}$ & $0,846^{* * *}$ & $0,834^{* * *}$ & 0,996 \\
\hline & $(0,006)$ & $(0,010)$ & $(0,017)$ & $(0,010)$ & $(0,032)$ \\
\hline \multirow{2}{*}{ NORDESTE } & $1,033^{\star \star \star}$ & 1,003 & $1,066^{\star \star *}$ & 1,016 & 1,034 \\
\hline & $(0,009)$ & $(0,016)$ & $(0,025)$ & $(0,015)$ & $(0,035)$ \\
\hline \multirow{2}{*}{ CENTRO_OESTE } & 1 & 1 & 1 & 1 & 1 \\
\hline & (omitido) & (omitido) & (omitido) & (omitido) & (omitido) \\
\hline \multirow{2}{*}{ PUBLICA } & $1,225^{\star \star *}$ & & & & \\
\hline & $(0,007)$ & 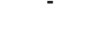 & - & - & 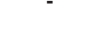 \\
\hline
\end{tabular}

Fonte: resultados estimados a partir de INEP (2009), INEP (2010a), INEP (2011), INEP (2012), INEP

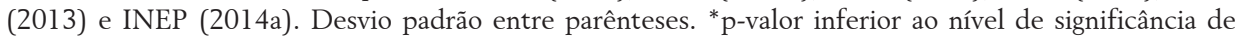
$0,10,{ }^{* * *}$ p-valor inferior ao nível de significância de 0,01 .

Pode-se perceber que formas seriadas para o acesso ao ensino superior, assim como a oferta de FIES e PROUNI integral nas universidades privadas, influenciam de forma positiva na permanência do estudante nesses cursos, uma vez que contribui na redução das restrições de crédito. Além disso, a presença dos auxílios moradia e permanência desempenham papel semelhante nas universidades públicas. 


\section{Considerações Finais}

A expansão do ensino superior brasileiro foi motivada, dentre outras razões, pelo diagnóstico do governo federal de que esse setor é fundamental para o desenvolvimento econômico. Acompanhada dessa ampliação, passou-se a investir mais recursos públicos na área: a verba para as universidades federais praticamente dobrou em um período de sete anos, enquanto que os recursos para o financiamento de cursos em instituições privadas aumentaram quase 15 vezes em um período de 14 anos. Porém, os resultados apresentados no decorrer deste ensaio mostram que uma das áreas definida como importante para a geração de novas tecnologias, a de ciências naturais e engenharia, apresenta uma taxa de evasão elevada. No momento em que o governo amplia o investimento na formação de capital humano e os estudantes não concluem os cursos, tem-se um desperdício de recursos públicos.

Como forma de evitar as elevadas taxas de abandono e alcançar os objetivos propostos pela expansão do ensino superior, torna-se importante conhecer as características dos estudantes que podem influenciar a decisão de evadir. Dessa forma, baseando-se em trabalhos já publicados no exterior sobre o tema, buscou-se identificar quais as variáveis que podem estar associadas, de forma negativa ou positiva, na decisão de abandonar ou permanecer, nos cursos de ciências naturais e tecnologia. Para isso, empregou-se a metodologia de Análise de Sobrevivência, que originou resultados condizentes com os apresentados pela literatura nacional e internacional. As estimativas mostraram que os estudantes mais integrados com o meio acadêmico por meio da realização de atividades remuneradas e não remuneradas, e os que recebem benefícios financeiros para auxiliar com os custos do curso evadiram menos.

Isso mostra que algumas medidas que já estão sendo tomadas para tentar aumentar a retenção, como a presença das bolsas que são mantidas por meio de recursos do PNAES. Porém, ainda não são suficientes, por serem necessárias políticas de melhorias da qualidade do ensino fundamental e médio. Portanto, a partir de estudos como este ensaio, os diferentes atores envolvidos nesse contexto podem identificar o que causa a evasão para grupos específicos e formular ações e políticas públicas que tenham por objetivo reverter esse cenário. 


\section{Referências}

Adachi, Ana Amélia Chaves Teixeira. 2009. "Evasão e evadidos nos cursos de graduação da Universidade Federal de Minas Gerais”. 214f. Dissertação (Mestrado em Educação) - Programa de Pós-Graduação em Educação, Universidade Federal de Minhas Gerais (UFMG), Belo Horizonte.

ANDIFES/ABRUEM/SESu/MEC. 1996. "Diplomação, Retenção e Evasão nos Cursos de Graduação em Instituições de Ensino Superior Públicas”. Comissão Especial de Estudos sobre a Evasão nas Universidades Públicas Brasileiras.

Andriola, Wagner Bandeira; Andriola, Cristiany Gomes; Moura, Cristiane Pascoal. 2006. "Opiniões de docentes e de coordenadores acerca do fenômeno da evasão discente dos cursos de graduação da Universidade Federal do Ceará (UFC)". Ensaio: Avaliação e Políticas Públicas em Educação 14 (52): 365-382.

http://www.scielo.br/pdf/ensaio/v14n52/a06v1452.pdf. (Acesso em: 10 de novembro de 2017).

Bean, John; Bradley, Russel. 1986. "Untangling the Satisfaction-Performance Relationship for College Students". The Journal of Higher Education 57 (4): 393-412. https://www.jstor.org/stable/1980994? seq=1\#page_scan_tab_ contents. (Acesso em: 05 de novembro de 2016).

Bettinger, Eric. 2004. "How Financial Aid Affects Persistence”. NBER Working Paper Series: Working Paper No.10242.

Bound, John; Lovenheim, Michael e Turner, Sarah. 2009. "Why have college completion rates declined? An analysis of changing student preparation and collegiate resources". NBER Working Paper Series: Working Paper No. 15566.

Brasil. 2001. "FIES: Prestação de contas ordinárias anual - Relatório de gestão do exercício de 2000”. http:// portal.mec.gov.br/index.php?option=com_docman \&view=download\&alias=17548-fies-relatorio-de-gestao-2000\&category_slug=maio-2015-pdf\&Itemid=30192. (Acesso em: 12 de maio 2016).

.2010. Decreto no 7.234, de 19 de julho de 2010. "Dispõe sobre o Programa Nacional de Assistência Estudantil (PNAES)".

www.planalto.gov.br/ccivil_03/_Ato2007-10/2010/Decreto/D7234.htm. (Acesso em: 26 de abril de 2016).

.2012. “Análise sobre a Expansão das Universidades Federais: 2003 a 2012”. Brasília: MEC. http:// portal.mec.gov.br/index.php?option $=$ com_docman\&task $=$ doc_download\&gid=12386\&Itemid=. $($ Acesso em: 30 de agosto de 2015).

. 2014. "Relatório de Avaliação da Execução de Programas de Governo n 35: Programa Universidade Para Todos - PROUNI".

http://sistemas2.cgu.gov.br/relats/uploads/6954_\%20RAv\%2035.pdf. (Acesso em: 15 de setembro de 2016).

2015. "FIES: Prestação de contas ordinárias anual - Relatório de gestão do exercício de 2014".

http://portal.mec.gov.br/index.php?option=com_docman\&view=download\&alias=17528-ies-relatorio-gestao-pcoa-exercicio-2014-tcu\&category_slug=maio-2015-pdf\&Itemid=30192. (Acesso em: 12 de maio de 2016).

Cameron, A. Colin; Trivedi, Pravin. 2005. Microeconometrics: methods and applications. New York: Cambridge University Press.

Chen, Xianglei; Soldner, Matthew. 2013. "STEM Attrition: College Students' Paths Into and Out of STEM Fields". National Center for Education Statistics, Institute of Education Sciences, U.S. Department of Education.

Desjardins, Stephen; Ahlburg, D.; Mccall, B. 1999. “An event history model of student departure”. Economics of Education Review 18 (3): 375-390.

2002. "Simulating the Longitudinal Effects of changes in Financial Aid on Student Departure from College". The Journal of Human Resources 37 (3): 653- 679.

Felder, Richard; et al. 1993. "A longitudinal study of engineering student performance and retention: Success and failure in the introductory course". Journal of Engineering Education 82 (1): 15-21. 
Fregoneis, Jucelia Geni Pereira. 2002. "Estudo do Desempenho Acadêmico nos Cursos de Graduação dos Centros de Ciências Exatas e de Tecnologia da Universidade Estadual de Maringá: período 1995 - 2000". Dissertação (Mestrado em Engenharia de Produção) - Programa de Pós-Graduação em Engenharia de Produção, Universidade Federal de Santa Catarina (UFSC), Florianópolis.

Hosmer Jr., David; Lameshow, Stanley. 1999. Applied Survival Analysis: Regression Modeling to Time to Event Data. New York: John Wiley \& sons, Inc.

Instituto Nacional de Estudos e Pesquisas Educacionais Anísio Teixeira - INEP. 2008. "Portaria no 55, de 3 de abril de 2008". http://portal.inep.gov.br/artigo//asset_publisher/B4AQV9zFY7Bv/content/enem-2008-inscricoes-estao-abertas/21206>. (Acesso em: 5 de novembro de 2017).

. 2009. Microdados do Censo da Educação Superior 2009. http://www.censosuperior.inep.gov.br/. (Acesso em: 27 de abril de 2016).

. 2010a. Microdados do Censo da Educação Superior 2010.

http://www.censosuperior.inep.gov.br/. (Acesso em: 27 de abril de 2016).

.2010b. Investimentos por Aluno por Nível de Ensino: Valores Reais.

http://portal.inep.gov.br/c/journal/view_article_content?groupId=10157\&articleId=24543\&version=1.0. (Acesso em: 27 de abril de 2016).

2011. Microdados do Censo da Educação Superior 2011.

http://www.censosuperior.inep.gov.br/. (Acesso em: 27 de abril de 2016).

2012. Microdados do Censo da Educação Superior 2012. http://www.censosuperior.inep.gov.br/.

(Acesso em: 27 de abril de 2016).

. 2013. Microdados do Censo da Educação Superior 2013. http://www.censosuperior.inep.gov.br/. (Acesso em: 27 de abril de 2016).

. 2014a. Microdados do Censo da Educação Superior 2014. http://www.censosuperior.inep.gov.br/. (Acesso em: 27 de abril de 2016).

. 2014b. Índice Geral de Cursos de 2014.

http://portal.inep.gov.br/basica-levantamentos-acessar. (Acesso em: 27 de abril de 2016).

Ishitani, Terry. 2003. "A Longitudinal Approach to Assessing Attrition Behavior among First- Generation Students: Time-Varying Effects of Pre-College Characteristics". Research in Higher Education 44 (4): 433-449.

Jenkins, Stephen. 2005. Survival Analysis. Mimeo, University of Essex. https://www.iser.essex.ac.uk/files/teaching/stephenj/ec968/pdfs/ec9681notesv6.pdf. (Acesso em: 15 de setembro de 2016).

Kaplan, E. L.; Meier, Paul. 1958. "Nonparametric Estimation from Incomplete Observations". Journal of the American Statistical Association 53 (282): 457-481.

Lee, Elisa; Wang, John. 2003. Statistical Methods for Survival Data Analysis. $3^{\text {a }}$ edição. Nova Jersey: John Wiley \& Sons, Inc.

Lima Jr., Paulo; Silveira, Fernando Lang da; Ostermann, Fernanda. 2002. "Análise de Sobrevivência aplicada ao estudo do fluxo escolar nos cursos e graduação em física: um exemplo de uma universidade brasileira". Revista Brasileira de Ensino em Física 34 (1): 1-10.

Mendes Junior, Álvaro Alberto Ferreira. 2014. "Uma análise da progressão dos alunos cotistas sob a primeira ação afirmativa brasileira no ensino superior: o caso da Universidade do Estado do Rio de Janeiro". Ensaio: Avaliação e Políticas Públicas em Educação 22 (82): 31-56.

Murdock, Tulisse. 1989. "Does Financial Aid Really Have an Effect on Student Retention?” Journal of Student Financial Aid, 19 (1), article 1. http://publications.nasfaa.org/jsfa/vol19/iss1/1. (Acesso em: 20 de setembro de 2016). Murtaugh, Paul; Burns, Leslie; Schuster, Jill. 1999. "Predicting the Retention of University Students". Research in Higher Education 40 (3): 355-371. 
Nora, Amaury. 1990. "Campus-based Aid Programs as Determinants of Retention among Hispanic Community College Students". The Journal of Higher Education 61 (3): 312-331.

Organização para a Cooperação e Desenvolvimento Econômico - OCDE. 2015. OECD Education at a Glance. http://www.oecd.org/edu/education-at-a-glance-2015.htm. (Acesso em: 15 de setembro de 2016).

Radcliffe, Peter; Huesman, Ronald; Kellogg, John. 2006. "Modeling the incidence and timing of student attrition: A survival analysis approach to retention analysis." Paper presented at the annual meeting of the Association for Institutional Research in the Upper Midwest (AIRUM).

Santelices, María Verónica; et al. 2016. "Determinants of persistence and the role of financial aid: lessons from Chile". Higher Education 71 (3): 323-342.

Silva, Glauco Peres da. 2013. "Análise de Evasão no Ensino Superior: uma proposta de diagnóstico de seus determinantes". Avaliação: Revista da Avaliação da Educação Superior, 18 (2): 311-333. http://www.scielo.br/ pdf/aval/v18n2/04.pdf. (Acesso em: 10 de novembro de 2017).

Smith, Jeremy; Naylor, Robin. 2011. "Dropping Out of University: A Statistical Analysis of the Probability of Withdrawal for UK University Students". Journal of the Royal Statistical Society, 164 (2): 389-405.

St. John, Edward, Hu, Shouping; Weber, Jeff. 2001. "State policy on the affordability of public higher education: the influence of state grants on persistence in Indiana". Research in Higher Education 42 (4): 401-428.

STATACORP. 2013. "Stata: Release 13". Statistical Software. College Station, TX: StataCorp LP. http://www. stata.com/manuals13/st.pdf. (Acesso em: 15 de setembro de 2016.)

Stinebrickner, Ralph; Stinebrickner, Todd. 2013a. "A Major in Science? Initial Beliefs and Final Outcomes for College Major and Dropout”. Oxford University Press: The Review of Economic Studies Advance Access.

.2013b. "Academic performance and college dropout: Using longitudinal expectations data to estimate a learning model. NBER Working Paper Series: Working Paper 18945. 


\section{Anexos}

Tabela 10 - Estatísticas Descritivas: curso de instituições públicas

\begin{tabular}{|c|c|c|c|c|c|c|c|c|c|c|c|c|}
\hline \multicolumn{13}{|c|}{ Cursos de cinco anos } \\
\hline & \multicolumn{2}{|c|}{2009} & \multicolumn{2}{|c|}{2010} & \multicolumn{2}{|c|}{2011} & \multicolumn{2}{|c|}{2012} & \multicolumn{2}{|c|}{2013} & \multicolumn{2}{|c|}{2014} \\
\hline & $\mu$ & $\sigma$ & $\mu$ & $\sigma$ & $\mu$ & $\sigma$ & $\mu$ & $\sigma$ & $\mu$ & $\sigma$ & $\mu$ & $\sigma$ \\
\hline OUTRO_INGRESSO & 0,122 & 0,328 & 0,113 & 0,316 & 0,113 & 0,317 & 0,104 & 0,305 & 0,096 & 0,295 & 0,088 & 0,283 \\
\hline INGRESSO_ENEM & 0,051 & 0,220 & 0,044 & 0,206 & 0,048 & 0,214 & 0,048 & 0,215 & 0,047 & 0,213 & 0,048 & 0,215 \\
\hline OCDE_4 & 0,121 & 0,326 & 0,081 & 0,273 & 0,082 & 0,275 & 0,079 & 0,271 & 0,075 & 0,267 & 0,065 & 0,247 \\
\hline OCDE_5 & 0,878 & 0,326 & 0,918 & 0,273 & 0,917 & 0,275 & 0,92 & 0,271 & 0,925 & 0,267 & 0,934 & 0,247 \\
\hline CONCORRIDO & 0,78 & 0,413 & 0,787 & 0,408 & 0,789 & 0,407 & 0,8 & 0,399 & 0,801 & 0,399 & 0,804 & 0,396 \\
\hline NOTURNO & 0,254 & 0,435 & 0,231 & 0,421 & 0,226 & 0,418 & 0,199 & 0,399 & 0,195 & 0,396 & 0,199 & 0,399 \\
\hline INTEGRAL & 0,59 & 0,491 & 0,64 & 0,479 & 0,649 & 0,477 & 0,684 & 0,464 & 0,693 & 0,46 & 0,697 & 0,459 \\
\hline \multicolumn{13}{|c|}{ Cursos de quatro anos } \\
\hline & \multicolumn{2}{|c|}{2009} & \multicolumn{2}{|c|}{2010} & \multicolumn{2}{|c|}{2011} & \multicolumn{2}{|c|}{2012} & \multicolumn{2}{|c|}{2013} & \multicolumn{2}{|c|}{2014} \\
\hline & $\mu$ & $\sigma$ & $\mu$ & $\sigma$ & $\mu$ & $\sigma$ & $\mu$ & $\sigma$ & $\mu$ & $\sigma$ & $\mu$ & $\sigma$ \\
\hline OUTRO_INGRESSO & 0,152 & 0,359 & 0,121 & 0,326 & 0,119 & 0,324 & 0,108 & 0,311 & 0,104 & 0,304 & 0,111 & 0,315 \\
\hline INGRESSO_ENEM & 0,056 & 0,231 & 0,057 & 0,232 & 0,060 & 0,239 & 0,064 & 0,245 & 0,056 & 0,231 & 0,048 & 0,215 \\
\hline OCDE_4 & 0,856 & 0,351 & 0,835 & 0,37 & 0,821 & 0,382 & 0,818 & 0,385 & 0,782 & 0,412 & 0,745 & 0,435 \\
\hline OCDE_5 & 0,143 & 0,351 & 0,164 & 0,37 & 0,178 & 0,382 & 0,181 & 0,385 & 0,217 & 0,412 & 0,745 & 0,435 \\
\hline CONCORRIDO_ & 0,756 & 0,429 & 0,758 & 0,428 & 0,759 & 0,427 & 0,772 & 0,419 & 0,781 & 0,413 & 0,778 & 0,415 \\
\hline NOTURNO & 0,299 & 0,287 & 0,249 & 0,432 & 0,237 & 0,425 & 0,225 & 0,418 & 0,215 & 0,411 & 0,198 & 0,316 \\
\hline INTEGRAL & 0,529 & 0,457 & 0,563 & 0,495 & 0,556 & 0,498 & 0,561 & 0,496 & 0,564 & 0,495 & 0,56 & 0,399 \\
\hline
\end{tabular}

Fonte: tabela elaborada a partir de INEP (2009), INEP (2010a), INEP (2011), INEP (2012b), INEP (2013a) e INEP (2014a).

Tabela 11- Estatísticas Descritivas: instituição pública

\begin{tabular}{|c|c|c|c|c|c|c|c|c|c|c|c|c|}
\hline \multicolumn{13}{|c|}{ Cursos de cinco anos } \\
\hline & \multicolumn{2}{|c|}{2009} & \multicolumn{2}{|c|}{2010} & \multicolumn{2}{|c|}{2011} & \multicolumn{2}{|c|}{2012} & \multicolumn{2}{|c|}{2013} & \multicolumn{2}{|c|}{2014} \\
\hline & $\mu$ & $\sigma$ & $\mu$ & $\sigma$ & $\mu$ & $\sigma$ & & $\sigma$ & & $\sigma$ & & $\sigma$ \\
\hline LABORATORIO & 0,920 & 0,271 & 0,916 & 0,278 & 0,916 & 0,278 & 0,911 & 0,285 & 0,911 & 0,285 & 0,916 & 0,278 \\
\hline ACESSIBILIDADE & 0,952 & 0,215 & 0,951 & 0,217 & 0,950 & 0,218 & 0,950 & 0,218 & 0,951 & 0,216 & 0,955 & 0,207 \\
\hline BIBLIOTECA & 0,981 & 0,136 & 0,979 & 0,143 & 0,979 & 0,144 & 0,976 & 0,152 & 0,975 & 0,156 & 0,978 & 0,147 \\
\hline SUL & 0,271 & 0,444 & 0,236 & 0,424 & 0,238 & 0,426 & 0,218 & 0,413 & 0,219 & 0,413 & 0,215 & 0,411 \\
\hline NORTE & 0,047 & 0,212 & 0,047 & 0,213 & 0,048 & 0,214 & 0,052 & 0,222 & 0,049 & 0,217 & 0,052 & 0,221 \\
\hline SUDESTE & 0,442 & 0,497 & 0,455 & 0,498 & 0,446 & 0,497 & 0,455 & 0,498 & 0,461 & 0,498 & 0,465 & 0,499 \\
\hline NORDESTE & 0,200 & 0,400 & 0,219 & 0,413 & 0,225 & 0,417 & 0,229 & 0,420 & 0,222 & 0,416 & 0,227 & 0,419 \\
\hline CENTRO_OESTE & 0,040 & 0,197 & 0,043 & 0,202 & 0,044 & 0,204 & 0,046 & 0,210 & 0,048 & 0,214 & 0,041 & 0,197 \\
\hline \multicolumn{13}{|c|}{ Cursos de quatro anos } \\
\hline & \multicolumn{2}{|c|}{2009} & \multicolumn{2}{|c|}{2010} & \multicolumn{2}{|c|}{2011} & \multicolumn{2}{|c|}{2012} & \multicolumn{2}{|c|}{2013} & \multicolumn{2}{|c|}{2014} \\
\hline & $\mu$ & $\sigma$ & $\mu$ & $\sigma$ & $\mu$ & $\sigma$ & $\mu$ & $\sigma$ & $\mu$ & $\sigma$ & $\mu$ & $\sigma$ \\
\hline LABORATORIO & 0,842 & 0,365 & 0,827 & 0,379 & 0,834 & 0,372 & 0,835 & 0,371 & 0,839 & 0,368 & 0,837 & 0,370 \\
\hline ACESSIBILIDADE & 0,941 & 0,235 & 0,947 & 0,225 & 0,945 & 0,229 & 0,941 & 0,235 & 0,950 & 0,218 & 0,947 & 0,223 \\
\hline BIBLIOTECA & 0,935 & 0,247 & 0,950 & 0,218 & 0,948 & 0,222 & 0,945 & 0,228 & 0,948 & 0,222 & 0,947 & 0,223 \\
\hline SUL & 0,171 & 0,376 & 0,161 & 0,367 & 0,148 & 0,356 & 0,140 & 0,347 & 0,135 & 0,342 & 0,123 & 0,328 \\
\hline NORTE & 0,059 & 0,235 & 0,049 & 0,216 & 0,052 & 0,222 & 0,059 & 0,236 & 0,060 & 0,238 & 0,071 & 0,258 \\
\hline SUDESTE & 0,413 & 0,492 & 0,387 & 0,487 & 0,387 & 0,487 & 0,392 & 0,488 & 0,384 & 0,486 & 0,358 & 0,479 \\
\hline NORDESTE & 0,229 & 0,420 & 0,272 & 0,445 & 0,279 & 0,449 & 0,286 & 0,452 & 0,300 & 0,458 & 0,322 & 0,467 \\
\hline CENTRO_OESTE & 0,129 & 0,335 & 0,131 & 0,338 & 0,134 & 0,340 & 0,123 & 0,329 & 0,120 & 0,325 & 0,126 & 0,332 \\
\hline
\end{tabular}

Fonte: tabela elaborada a partir de INEP (2009), INEP (2010a), INEP (2011), INEP (2012b), INEP (2013a) e INEP (2014a). 
Tabela 12 - Estatísticas Descritivas: curso de instituições privadas

\begin{tabular}{|c|c|c|c|c|c|c|c|c|c|c|c|c|}
\hline \multicolumn{13}{|c|}{ Cursos de cinco anos } \\
\hline & \multicolumn{2}{|c|}{2009} & \multicolumn{2}{|c|}{2010} & \multicolumn{2}{|c|}{2011} & \multicolumn{2}{|c|}{2012} & \multicolumn{2}{|c|}{2013} & \multicolumn{2}{|c|}{2014} \\
\hline & $\mu$ & $\sigma$ & $\mu$ & $\sigma$ & $\mu$ & $\sigma$ & $\mu$ & $\sigma$ & $\mu$ & $\sigma$ & $\mu$ & $\sigma$ \\
\hline OUT_INGRESSO & 0,189 & 0,391 & 0,191 & 0,393 & 0,201 & 0,400 & 0,199 & 0,399 & 0,184 & 0,388 & 0,174 & 0,379 \\
\hline INGRESSO_ENEM & 0,144 & 0,351 & 0,137 & 0,344 & 0,122 & 0,328 & 0,120 & 0,325 & 0,126 & 0,332 & 0,136 & 0,343 \\
\hline OCDE_4 & 0,019 & 0,137 & 0,008 & 0,094 & 0,007 & 0,086 & 0,008 & 0,09 & 0,007 & 0,088 & 0,007 & 0,085 \\
\hline OCDE_5 & 0,98 & 0,137 & 0,991 & 0,094 & 0,992 & 0,086 & 0,991 & 0,09 & 0,992 & 0,088 & 0,992 & 0,085 \\
\hline NOTURNO & 0,891 & 0,31 & 0,88 & 0,324 & 0,873 & 0,332 & 0,863 & 0,343 & 0,859 & 0,347 & 0,849 & 0,357 \\
\hline INTEGRAL & 0,072 & 0,259 & 0,073 & 0,261 & 0,077 & 0,267 & 0,079 & 0,27 & 0,081 & 0,273 & 0,085 & 0,28 \\
\hline \multicolumn{13}{|c|}{ Cursos de quatro anos } \\
\hline & \multicolumn{2}{|c|}{2009} & \multicolumn{2}{|c|}{2010} & \multicolumn{2}{|c|}{2011} & \multicolumn{2}{|c|}{2012} & \multicolumn{2}{|c|}{2013} & \multicolumn{2}{|c|}{2014} \\
\hline & $\mu$ & $\sigma$ & $\mu$ & $\sigma$ & $\mu$ & $\sigma$ & $\mu$ & $\sigma$ & $\mu$ & $\sigma$ & $\mu$ & $\sigma$ \\
\hline OUT_INGRESSO & 0,173 & 0,378 & 0,172 & 0,378 & 0,173 & 0,378 & 0,168 & 0,374 & 0,169 & 0,375 & 0,172 & 0,377 \\
\hline INGRESSO_ENEM & 0,137 & 0,343 & 0,129 & 0,336 & 0,125 & 0,331 & 0,124 & 0,330 & 0,123 & 0,329 & 0,107 & 0,309 \\
\hline OCDE_4 & 0,906 & 0,291 & 0,889 & 0,313 & 0,883 & 0,32 & 0,883 & 0,321 & 0,854 & 0,352 & 0,844 & 0,362 \\
\hline OCDE_5 & 0,093 & 0,291 & 0,110 & 0,313 & 0,116 & 0,32 & 0,116 & 0,321 & 0,145 & 0,352 & 0,155 & 0,362 \\
\hline NOTURNO & 0,903 & 0,287 & 0,903 & 0,291 & 0,903 & 0,295 & 0,9 & 0,299 & 0,897 & 0,302 & 0,895 & 0,306 \\
\hline INTEGRAL & 0,051 & 0,213 & 0,051 & 0,215 & 0,051 & 0,221 & 0,055 & 0,228 & 0,063 & 0,243 & 0,065 & 0,247 \\
\hline
\end{tabular}

Fonte: tabela elaborada a partir de INEP (2009), INEP (2010a), INEP (2011), INEP (2012b), INEP (2013a) e INEP (2014a).

Tabela 13 - Estatísticas Descritivas: aluno de instituições públicas

\begin{tabular}{|c|c|c|c|c|c|c|c|c|c|c|c|c|}
\hline \multicolumn{13}{|c|}{ Cursos de cinco anos } \\
\hline & \multicolumn{2}{|c|}{2009} & \multicolumn{2}{|c|}{2010} & \multicolumn{2}{|c|}{2011} & \multicolumn{2}{|c|}{2012} & \multicolumn{2}{|c|}{2013} & \multicolumn{2}{|c|}{2014} \\
\hline & $\mu$ & $\sigma$ & $\mu$ & $\sigma$ & $\mu$ & $\sigma$ & $\mu$ & $\sigma$ & $\mu$ & $\sigma$ & $\mu$ & $\sigma$ \\
\hline SEXO & 0,336 & 0,472 & 0,331 & 0,470 & 0,339 & 0,474 & 0,339 & 0,474 & 0,343 & 0,475 & 0,338 & 0,473 \\
\hline IDADE & 20,68 & 4,42 & 21,55 & 4,282 & 22,40 & 4,071 & 23,24 & 3,852 & 24,10 & 3,722 & 25,10 & 3,717 \\
\hline MORADIA & 0,008 & 0,091 & 0,019 & 0,138 & 0,020 & 0,141 & 0,024 & 0,154 & 0,017 & 0,129 & 0,013 & 0,114 \\
\hline BOLSA_PERM & 0,005 & 0,071 & 0,014 & 0,118 & 0,009 & 0,095 & 0,014 & 0,119 & 0,019 & 0,138 & 0,022 & 0,147 \\
\hline AT_REMUNERADA & 0,017 & 0,128 & 0,056 & 0,229 & 0,091 & 0,287 & 0,108 & 0,310 & 0,151 & 0,358 & 0,099 & 0,299 \\
\hline AT_N_REMUNERADA & 0,023 & 0,15 & 0,036 & 0,187 & 0,058 & 0,233 & 0,055 & 0,229 & 0,055 & 0,229 & 0,046 & 0,210 \\
\hline \multicolumn{13}{|c|}{ Cursos de quatro anos } \\
\hline & \multicolumn{2}{|c|}{2009} & \multicolumn{2}{|c|}{2010} & \multicolumn{2}{|c|}{2011} & \multicolumn{2}{|c|}{2012} & \multicolumn{2}{|c|}{2013} & \multicolumn{2}{|c|}{2014} \\
\hline & $\mu$ & $\sigma$ & $\mu$ & $\sigma$ & $\mu$ & $\sigma$ & $\mu$ & $\sigma$ & $\mu$ & $\sigma$ & $\mu$ & $\sigma$ \\
\hline SEXO & 0,379 & 0,485 & 0,366 & 0,482 & 0,367 & 0,482 & 0,376 & 0,484 & 0,365 & 0,481 & 0,338 & 0,473 \\
\hline IDADE & 21,457 & 5,204 & 22,082 & 4,815 & 22,925 & 4,675 & 23,720 & 4,473 & 24,638 & 4,401 & 25,748 & 4,567 \\
\hline MORADIA & 0,011 & 0,104 & 0,016 & 0,126 & 0,021 & 0,145 & 0,027 & 0,162 & 0,016 & 0,125 & 0,014 & 0,117 \\
\hline BOLSA_PERM & 0,009 & 0,094 & 0,015 & 0,121 & 0,016 & 0,124 & 0,020 & 0,142 & 0,018 & 0,134 & 0,025 & 0,155 \\
\hline AT_REMUN & 0,025 & 0,155 & 0,071 & 0,258 & 0,116 & 0,321 & 0,141 & 0,348 & 0,129 & 0,335 & 0,092 & 0,290 \\
\hline AT_N_REMUN & 0,014 & 0,119 & 0,041 & 0,199 & 0,052 & 0,222 & 0,066 & 0,249 & 0,066 & 0,249 & 0,039 & 0,193 \\
\hline
\end{tabular}

Fonte: tabela elaborada a partir de INEP (2009), INEP (2010a), INEP (2011), INEP (2012b), INEP (2013a) e INEP (2014a). 
Tabela 14 - Estatísticas Descritivas: instituição privada

\begin{tabular}{|c|c|c|c|c|c|c|c|c|c|c|c|c|}
\hline \multicolumn{13}{|c|}{ Cursos de cinco anos } \\
\hline & \multicolumn{2}{|c|}{2009} & \multicolumn{2}{|c|}{2010} & \multicolumn{2}{|c|}{2011} & \multicolumn{2}{|c|}{2012} & \multicolumn{2}{|c|}{2013} & \multicolumn{2}{|c|}{2014} \\
\hline & $\mu$ & $\sigma$ & $\mu$ & $\sigma$ & $\mu$ & $\sigma$ & $\mu$ & $\sigma$ & $\mu$ & $\sigma$ & $\mu$ & $\sigma$ \\
\hline LAB & 0,991 & 0,094 & 0,993 & 0,085 & 0,998 & 0,046 & 0,998 & 0,047 & 0,998 & 0,044 & 0,998 & 0,047 \\
\hline ACESSIBILIDADE & 0,996 & 0,066 & 0,996 & 0,066 & 0,995 & 0,069 & 0,997 & 0,058 & 0,997 & 0,053 & 0,996 & 0,060 \\
\hline BIBLIOTECA & 0,982 & 0,133 & 0,980 & 0,139 & 0,979 & 0,143 & 0,976 & 0,152 & 0,973 & 0,161 & 0,982 & 0,132 \\
\hline SUL & 0,125 & 0,331 & 0,147 & 0,354 & 0,155 & 0,362 & 0,172 & 0,377 & 0,172 & 0,378 & 0,184 & 0,387 \\
\hline NORTE & 0,042 & 0,201 & 0,038 & 0,191 & 0,038 & 0,190 & 0,037 & 0,188 & 0,040 & 0,196 & 0,031 & 0,173 \\
\hline SUDESTE & 0,685 & 0,465 & 0,654 & 0,476 & 0,641 & 0,480 & 0,630 & 0,483 & 0,620 & 0,485 & 0,602 & 0,490 \\
\hline NORDESTE & 0,084 & 0,278 & 0,093 & 0,290 & 0,093 & 0,291 & 0,090 & 0,286 & 0,094 & 0,292 & 0,107 & 0,309 \\
\hline CENTRO_OESTE & 0,064 & 0,245 & 0,068 & 0,252 & 0,073 & 0,260 & 0,072 & 0,258 & 0,073 & 0,261 & 0,076 & 0,266 \\
\hline \multicolumn{13}{|c|}{ Cursos de quatro anos } \\
\hline & \multicolumn{2}{|c|}{2009} & \multicolumn{2}{|c|}{2010} & \multicolumn{2}{|c|}{2011} & \multicolumn{2}{|c|}{2012} & \multicolumn{2}{|c|}{2013} & \multicolumn{2}{|c|}{2014} \\
\hline & $\mu$ & $\sigma$ & $\mu$ & $\sigma$ & $\mu$ & $\sigma$ & $\mu$ & $\sigma$ & $\mu$ & $\sigma$ & $\mu$ & $\sigma$ \\
\hline LAB & 0,991 & 0,093 & 0,992 & 0,089 & 0,992 & 0,087 & 0,994 & 0,079 & 0,995 & 0,068 & 0,996 & 0,066 \\
\hline ACESSIBILIDADE & 0,993 & 0,082 & 0,993 & 0,085 & 0,994 & 0,080 & 0,993 & 0,084 & 0,992 & 0,088 & 0,990 & 0,097 \\
\hline BIBLIOTECA & 0,980 & 0,141 & 0,977 & 0,149 & 0,974 & 0,160 & 0,972 & 0,164 & 0,968 & 0,175 & 0,975 & 0,156 \\
\hline SUL & 0,122 & 0,328 & 0,139 & 0,346 & 0,143 & 0,350 & 0,149 & 0,356 & 0,159 & 0,366 & 0,173 & 0,378 \\
\hline NORTE & 0,049 & 0,215 & 0,047 & 0,211 & 0,046 & 0,209 & 0,041 & 0,199 & 0,051 & 0,220 & 0,048 & 0,214 \\
\hline SUDESTE & 0,651 & 0,477 & 0,611 & 0,488 & 0,612 & 0,487 & 0,614 & 0,487 & 0,576 & 0,494 & 0,564 & 0,496 \\
\hline NORDESTE & 0,089 & 0,285 & 0,103 & 0,304 & 0,103 & 0,303 & 0,100 & 0,300 & 0,124 & 0,330 & 0,136 & 0,343 \\
\hline CENTRO_OESTE & 0,089 & 0,285 & 0,100 & 0,300 & 0,096 & 0,295 & 0,096 & 0,294 & 0,089 & 0,285 & 0,079 & 0,270 \\
\hline
\end{tabular}

Fonte: tabela elaborada a partir de INEP (2009), INEP (2010a), INEP (2011), INEP (2012b), INEP (2013a) e INEP (2014a).

Tabela 15 - Estatísticas Descritivas: aluno de instituições privadas

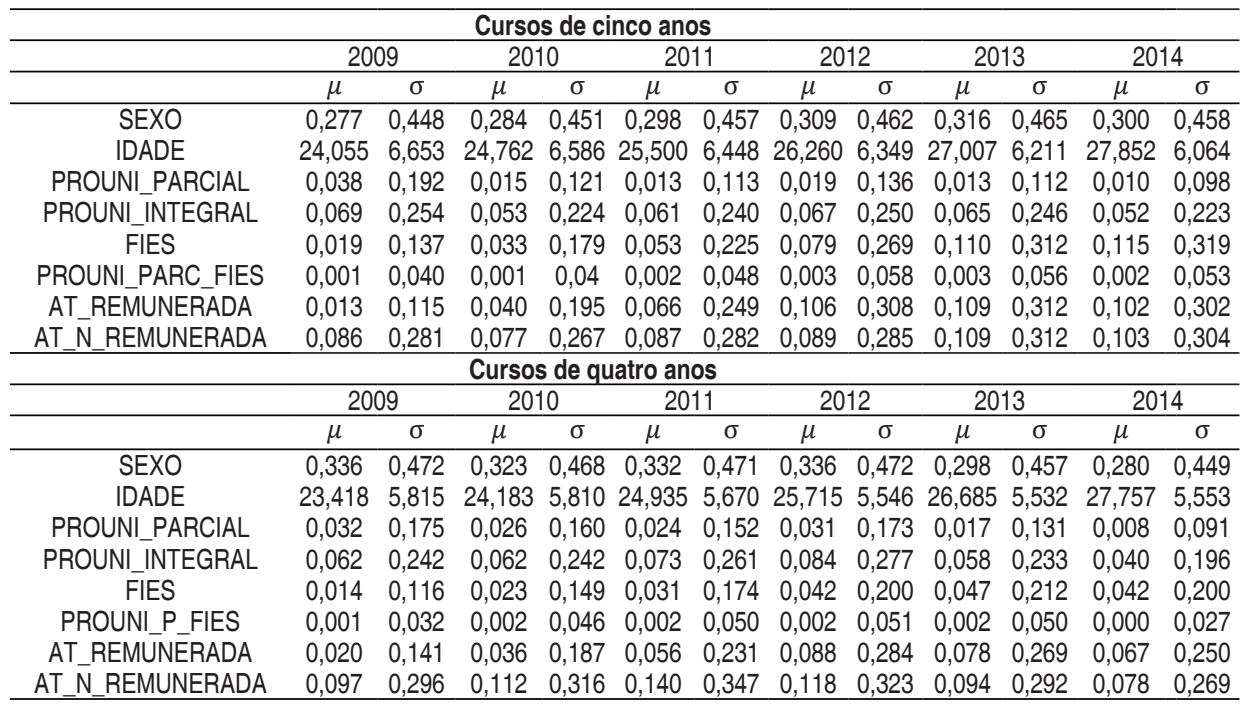

Fonte: tabela elaborada a partir de INEP (2009), INEP (2010a), INEP (2011), INEP (2012b), INEP (2013a) e INEP (2014a). 